\title{
Disturbed Prefrontal Cortex Activity in the Absence of Schizophrenia-Like Behavioral Dysfunction in Arc/Arg3.1 Deficient Mice
}

\author{
ĐDiaoyan Gao, ${ }^{1}$ Jasper Grendel, ${ }^{1}$ Mary Muhia, ${ }^{2}$ Sergio Castro-Gomez, ${ }^{1}$ Ute Süsens, ${ }^{1}{ }^{\circledR D}$ Dirk Isbrandt, ${ }^{3,4,5}$ \\ Matthias Kneussel, ${ }^{2}$-Dietmar Kuhl, ${ }^{1}$ and ${ }^{\circ}$ Ora Ohana ${ }^{1}$ \\ ${ }^{1}$ Institute for Molecular and Cellular Cognition, ${ }^{2}$ Institute for Molecular Neurogenetics, ${ }^{3}$ Experimental Neuropediatrics, Center for Molecular Neurobiology \\ Hamburg, University Medical Center Hamburg-Eppendorf, 20251 Hamburg, Germany, ${ }^{4}$ Institute for Molecular and Behavioral Neuroscience, University of \\ Cologne, 50937 Cologne, Germany, and ${ }^{5}$ Experimental Neurophysiology, German Center for Neurodegenerative Diseases, 53175 Bonn, Germany
}

Arc/Arg3.1, an activity regulated immediate early gene, is essential for learning and memory, synaptic plasticity, and maturation of neural networks. It has also been implicated in several neurodevelopmental disorders, including schizophrenia. Here, we used male and female constitutive and conditional Arc/Arg3.1 knock-out (KO) mice to investigate the causal relationship between Arc/Arg3.1 deletion and schizophrenia-linked neurophysiological and behavioral phenotypes. Using in vivo local field potential recordings, we observed dampened oscillatory activity in the prefrontal cortex (PFC) of the KO and early conditional KO (early-cKO) mice, in which Arc/Arg3.1 was deleted perinatally. Whole-cell patch-clamp recordings from neurons in PFC slices revealed altered synaptic properties and reduced network gain in the $\mathrm{KO}$ mice as possible mechanisms underlying the oscillation deficits. In contrast, we measured normal oscillatory activity in the PFC of late conditional KO (late-cKO) mice, in which Arc/Arg3.1 was deleted during late postnatal development. Our data show that constitutive Arc/Arg3.1 KO mice exhibit no deficit in social engagement, working memory, sensorimotor gating, native locomotor activity, and dopaminergic innervation. Moreover, adolescent social isolation, an environmental stressor, failed to induce deficits in sociability or sensorimotor gating in adult KO mice. Thus, genetic removal of Arc/Arg3.1 per se does not cause schizophrenia-like behavior. Prenatal or perinatal deletion of Arc/Arg3.1 alters cortical network activity, however, without overtly disrupting the balance of excitation and inhibition in the brain and not promoting schizophrenia. Misregulation of Arc/Arg3.1 rather than deletion could potentially tip this balance and thereby promote emergence of schizophrenia and other neuropsychiatric disorders.

Key words: Arc/Arg3.1; excitation/inhibition; knock-out; local field potential; prefrontal cortex; schizophrenia

\section{Significance Statement}

The activity-regulated and memory-linked gene Arc/Arg3.1 has been implicated in the pathogenesis of schizophrenia, but direct evidence and a mechanistic link are still missing. The current study asks whether loss of Arc/Arg3.1 can affect brain circuitry and cause schizophrenia-like symptoms in mice. The findings demonstrate that genetic deletion of $\mathrm{Arc} / \mathrm{Arg} 3.1$ before puberty alters synaptic function and prefrontal cortex activity. Although brain networks are disturbed, genetic deletion of Arc/Arg3.1 does not cause schizophrenia-like behavior, even when combined with an environmental insult. It remains to be seen whether misregulation of Arc/Arg3.1 might critically imbalance brain networks and lead to emergence of schizophrenia.

\section{Introduction}

Schizophrenia is a debilitating neuropsychiatric disease with a high penetration $(1 \%)$ of the population and a strong hereditary component. Although heterogeneous, the core behaviors characterizing schizophrenia are divided in positive symptoms, includ-

Received March 19, 2019; revised Aug. 6, 2019; accepted Aug. 29, 2019.

Author contributions: X.G., D.K., and 0.0. designed research; X.G., J.G., M.M., S.C.-G., U.S., D.I., and 0.0. performed research; D.K. contributed unpublished reagents/analytic tools; X.G., J.G., M.M., S.C.-G., D.I., M.K., D.K., and 0.0 . analyzed data; X.G., D.K., and 0.0 . wrote the paper. ing delusions and hallucinations, negative symptoms, including social withdrawal and anhedonia, and cognitive symptoms reflecting deficits in working memory and executive control (van Os and Kapur, 2009; Owen et al., 2016). The neurophysiological

This work was supported by the Grant "Molekulare Mechanismen der Netzwerkmodifizierung" to D.K. and 0.0. from the Federal State of Hamburg, by a Grant from the Schaller-Nikolich Foundation to D.K. and 0.0., by the DFG Grant KN556/11-2 (F0R2419) to M.K.X.G. was supported by a scholarship from the Chinese government awarded by the China Scholarship Council. We thank Sabine Hoffmeister-Ulrich for performing CNV on Cre recombinase carrying mice and to Peter Soba for assistance with Imaris. Confocal images were taken in the Microscopy Imaging Facility of the University Medical Center Hamburg-Eppendorf with technical support from Antonio Virgilio Failla. 
characteristics of the disease include altered brain activity patterns and uncoordinated inter-areal communication (Lisman, 2012; Uhlhaas and Singer, 2015; Hunt et al., 2017). Although psychosis commonly manifests during puberty and early adulthood, cognitive and neurophysiological phenotypes can be detected earlier, which has led to the prevalent view of schizophrenia as a neurodevelopmental disorder (Rapoport et al., 2012; Birnbaum and Weinberger, 2017). This view holds that the process of normal brain development is interrupted by polygenetic and environmental factors (van Os and Kapur, 2009; Modai and Shomron, 2016; Owen et al., 2016), which ultimately alter neurotransmitter systems, brain connectivity, and cognitive functions.

The activity-regulated gene Arg3.1 (Link et al., 1995), also known as Arc (Lyford et al., 1995), plays an essential role in adult learning and memory and synaptic plasticity (Guzowski et al., 2000; Plath et al., 2006; Messaoudi et al., 2007; Jakkamsetti et al., 2013; El-Boustani et al., 2018; Gao et al., 2018). Additionally, Arc/Arg3.1 also mediates forms of plasticity that are prominent during development, such as homeostatic synaptic scaling (Chowdhury et al., 2006; Shepherd et al., 2006), metabotropic glutamate receptor-dependent long-term depression (Waung et al., 2008) and synapse elimination (Mikuni et al., 2013). Arc/ Arg3.1 upregulation during early postnatal development shapes hippocampal oscillatory activity and learning capacity (Gao et al., 2018), likely by changing network connectivity and microarchitecture. This may also explain why misregulation of Arc/Arg3.1 is linked to neurodevelopmental diseases, such as fragile X Syndrome (Niere et al., 2012; Ronesi et al., 2012) and Angelman syndrome (Greer et al., 2010; Cao et al., 2013; Mandel-Brehm et al., 2015). Previous studies on schizophrenia patients implicated Arc/Arg3.1 as a molecular hub in synaptic gene networks whose abnormalities possibly play a significant role in the pathogenesis of schizophrenia (Kirov et al., 2012; Fromer et al., 2014; Purcell et al., 2014; Fernández et al., 2017). In addition, a recent study (Managò et al., 2016) reported schizophrenia-like behaviors and dysregulated dopaminergic transmission in Arc/Arg3.1-deficient mice (Wang et al., 2006). However, the presence of a neomycin cassette and an EGFP sequence in the genome of these mice can result in artifactual aberrations in gene expression and confound the conclusions of the study.

Here, we used independently generated constitutive and conditional Arc/Arg3.1 knock-out (KO) mice to ask whether loss of Arc/Arg3.1 by itself is indeed sufficient to evoke neurophysiological and behavioral dysfunctions of schizophrenia. Alterations in cortical activity, in particular, aberrant gamma oscillations (Lisman, 2012; Uhlhaas and Singer, 2015; Hunt et al., 2017) are considered an endophenotype of schizophrenia and can be observed in prodromal stages of the disease, before manifestations of behavioral symptoms. Hence, we recorded local field potential (LFP) in the prefrontal cortex (PFC) of anesthetized WT and KO mice and compared these to conditional $\mathrm{KO}$ mice in which Arcl Arg3.1 was deleted after late postnatal development. We labeled synaptic proteins in the PFC and measured glutamatergic and GABAergic neurotransmission in PFC neurons to elucidate synaptic mechanisms underlying aberrant network activity and cognitive dysfunction. In addition, we assessed the behavior of adult

The authors declare no competing financial interests.

Correspondence should be addressed to Ora Ohana at ora.ohana@zmnh.uni-hamburg.de or Dietmar Kuhl at dietmar.kuhl@zmnh.uni-hamburg.de.

https://doi.org/10.1523/JNEUROSCI.0623-19.2019

Copyright $\odot 2019$ the authors
Arc/Arg3.1 KO mice in three benchmark tests of schizophrenia in rodents. Moreover, given the longstanding theory about the dysfunction of the dopamine system in schizophrenia (Toda and Abi-Dargham, 2007; Howes and Kapur, 2009; Howes et al., 2015), we examined the sensitivity to dopamine elevation and the dopaminergic innervation of the PFC and striatum. In humans, schizophrenia has a high rate of comorbidity with epilepsy (Mäkikyrö et al., 1998; Qin et al., 2005; Clarke et al., 2012), which is recapitulated in several animal models of the disease (Fejgin et al., 2014). To investigate a possible association between Arcl Arg3.1 deletion, epileptic activity, and schizophrenia, we performed electrocorticogram recordings from chronically implanted WT and KO mice while monitoring their activity over several days. Finally, we tested the interaction between Arc/Arg3.1 deletion and an environmental stressor on schizophrenia-like behaviors.

\section{Materials and Methods}

Mice. Mice aged 3-5 months were kept in a vivarium with an inverted $12 \mathrm{~h}$ light/dark cycle (08:00-20:00 dark period) in groups, under standard housing conditions $\left(23 \pm 1^{\circ} \mathrm{C}, 40-50 \%\right.$ humidity; food and water ad libitum). Animals were housed together in groups of 3-5 mice per cage. Mice subjected to social isolation were housed individually from postnatal day (P)35 until the day of the experiment. Both male and female mice were used in all experiments. All procedures were conducted in accordance with the German and European Community laws on protection of experimental animals and approved by the local authorities of the City of Hamburg. Experimenters were blind to the genotype until the conclusion of experiments and analysis.

Generation of constitutive and conditional Arc/Arg3.1 KO mice. Arc/ Arg3.1 KO mice were generated as previously described (Plath et al., 2006). Along with the KO mice generation, floxed Arc/Arg3.1 mutants $\left(\operatorname{Arc} / \operatorname{Arg} 3.1^{\mathrm{f} / f}\right)$ were generated in parallel and thoroughly validated for use in biochemical and behavioral experiments (Gao et al., 2018). Conditional Arc/Arg3.1 gene ablation in the brain was accomplished by breeding $\operatorname{Arc} / \operatorname{Arg} 3.1^{\text {fff }}$ with the Cre recombinase transgenic mice (1) $\operatorname{Tg}($ CaMKII $\alpha$-cre $) 1$ Gsc (Casanova et al., 2001) to obtain early conditional $\mathrm{KO}$ (early-cKO) mice, and (2) $\mathrm{Tg}($ CaMKII $\alpha$-cre $) \mathrm{T} 29-1$ Stl (Tsien et al., 1996) to obtain late conditional KO (late-cKO) mice. Breeding was performed in accordance with recommended procedure for LoxP-Cre recombination (Song and Palmiter, 2018). Briefly, in generation F1 Arcl Arg3. $1^{\text {f/f }}$ mice were crossed with Arc/Arg3. $1^{+/+, C r e+}$ mice. In generation F2 Arc/Arg3. $1^{f /+, C r e+}$ were crossed with $\operatorname{Arc} / \operatorname{Arg} 3.1^{f /+}$ to obtain cKO mice. Mice with genotypes $\operatorname{Arc} / \operatorname{Arg} 3.1^{+/+, C r e+}+$ and $\operatorname{Arc} / \operatorname{Arg} 3.1^{f / f, C r e+}$ were used for experiments as WT controls and cKOs, respectively. Mice were genotyped by PCR for Arc/Arg3.1 and by PCR and copy number variation for Cre. Genotyping was performed between P5 and P7 and again after termination of the experiment.

In vivo LFP recording in the PFC. LFP recording and analysis were performed as previously described (Prox et al., 2013; Fazeli et al., 2017). In short, adult male mice were injected with $0.8 \mathrm{mg} / \mathrm{g}$ body weight urethane ( $10 \% \mathrm{w} / \mathrm{v}$, in $0.9 \%$ sodium chloride; Sigma-Aldrich) and $0.05 \mu \mathrm{g} / \mathrm{g}$ body weight of buprenorphine (Temgesic). Initial anesthesia was induced with $4 \%$ isoflurane, which was decreased to $1.0-1.5 \%$ isoflurane during surgery. A linear 16-site silicon probe with a $100 \mu \mathrm{m}$ interelectrode distance and $177 \mu \mathrm{m}^{2}$ electrode surface (a1x16-5 mm-100177; NeuroNexus Technologies) was vertically lowered into the PFC of the right hemisphere $(1.5 \mathrm{~mm}$ anterior to bregma, $0.3 \mathrm{~mm}$ lateral to midline, $3.3 \mathrm{~mm}$ deep). Data from the probe was digitally filtered (0.5$9000 \mathrm{~Hz}$ bandpass) and digitized as 16-bit integers with a sampling rate of $32 \mathrm{kHz}$ using a Digital Lynx 4SX data acquisition system (NeuraLynx). During the recording, anesthetic depth was monitored from breathing rates, twitching and electrophysiological properties. If required, additional $0.2 \mathrm{mg} / \mathrm{g}$ body weight urethane doses were given. The position of the probe, dipped in a DiI-solution before insertion, was verified postmortem from NeuroTrace fluorescent DAPI-stained (Invitrogen) coro- 
nal slices. Analysis was performed from electrodes located in layer (L) 5 of the infralimbic (IL) region of the PFC.

All in vivo data were analyzed and visualized in MATLAB (MathWorks) or NeuroScope (Hazan et al., 2006). LFPs were downsampled to $1.28 \mathrm{kHz}$ from raw traces. Multitaper time-frequency spectra were computed using Chronux (http://chronux.org). One power spectrum per mouse was calculated from concatenated epochs $(\mathrm{nFFT}=4096, \mathrm{nw}=1)$. Theta $(3.8-6 \mathrm{~Hz})$ and gamma $(20-50 \mathrm{~Hz})$ power was calculated for selected rapid eye movement (REM)-like epochs by integrating the area below the theta and gamma ranges.

In vitro recordings in PFC slices. Mice, 3-4 months old, were anesthetized with isoflurane and decapitated. Brains were rapidly removed and immersed in ice-cold slicing artificial CSF (slicing-ACSF), continuously gassed with a mixture of $95 \% \mathrm{O}_{2}, 5 \% \mathrm{CO}_{2}$. Coronal slices $(350 \mu \mathrm{m})$ were cut (Microme $650 \mathrm{H}$ vibratome, ThermoFisher Scientific), immediately transferred into a holding chamber containing oxygenated warmed recording-ACSF and allowed to recover for $1-4 \mathrm{~h}$ at $36^{\circ} \mathrm{C}$. Slicing-ACSF contained the following (in mM): 212 sucrose, $2.6 \mathrm{KCl}, 1 \mathrm{CaCl}_{2}, 3 \mathrm{MgSO}_{4}$, $1.25 \mathrm{NaH}_{2} \mathrm{PO}_{4}, 26 \mathrm{NaHCO}_{3}, 10$ glucose. Recording-ACSF contained the following (in $\mathrm{mm}$ ): $119 \mathrm{NaCl}, 2.5 \mathrm{KCl}, 2.5 \mathrm{CaCl}_{2}, 1.3 \mathrm{MgSO}_{4}, 1.25$ $\mathrm{NaH}_{2} \mathrm{PO}_{4}, 26 \mathrm{NaHCO}_{3}, 10$ glucose, and was maintained at $37^{\circ} \mathrm{C}$ and pH 7.4.

Recordings were made in a submerged chamber continuously perfused with oxygenated recording-ACSF $(3 \mathrm{ml} / \mathrm{min}$ ) maintained at 35 $37^{\circ} \mathrm{C}$. Slices containing the PFC (bregma coordinates 1.4-2.2) were visualized with an inverted Olympus BX51WI microscope. A $4 \times$ objective was used to localize L5 in the IL or prelimbic (PrL) regions of the PFC and to place a stimulating electrode (concentric stainless steel, $0.1 \mathrm{M} \Omega$ impedance) in L1 of the same region. Neurons in L5 were visualized and targeted for patching with infrared differential interference contrast microscopy at $63 \times$ magnification. Pipettes $(5-8 \mathrm{M} \Omega$ ) were pulled from borosilicate glass and filled with a recording solution containing the following (in $\mathrm{mm}$ ): 115 potassium gluconate, $4 \mathrm{KCl}, 10$ HEPES, 10 phosphocreatine- $\mathrm{Na}_{4}$ ATP-Mg, 0.3 guanosine triphosphate, and $0.5 \%$ biocytin. Osmolarity was adjusted to $280-290 \mathrm{mOsm}$ with $\mathrm{KOH}$. This solution was chosen to increase the driving force for $\mathrm{Cl}^{-}$currents (calculated as $-82 \mathrm{mV}$ ) and facilitate detection of spontaneous IPSCs (sIPSCs) Somatic whole-cell patch-clamp recordings were made in current- and voltage-clamp modes with a MultiClamp 700b amplifier (Molecular Devices). Signals were sampled at $10 \mathrm{kHz}$ and filtered $(3 \mathrm{kHz})$ using Digidata 1422 (Molecular Devices). Series resistance (range 12-40 $\mathrm{M} \Omega$ ) was monitored continuously but compensated only in the current clap mode. Experiments where Rs changed $>30 \%$ were excluded from analysis Data were collected and visualized using the pCLAMP 10 software (Molecular Devices), exported and analyzed off-line, using Clampfit10 and IGOR Pro 6.3 (WaveMetrics). A typical experiment consisted of a series of hyperpolarizing and depolarizing currents steps in currentclamp, to determine the input resistance (Rin) of the cell and its action potential firing pattern and frequency. Subsequently, neurons were voltage clamped at membrane potential of -70 and $-50 \mathrm{mV}$ to measure spontaneous EPSCs (sEPSCs) and sIPSCs, respectively. sIPSCs recorded at $-50 \mathrm{mV}$ were consistently abolished following application of the $\mathrm{GABA}_{\mathrm{A}}$ antagonist gabazine $(10 \mu \mathrm{M} ; \mathrm{Abcam})$. To measure evoked PSCs (ePSCs), neurons were clamped to $-70 \mathrm{mV}$ and a series of incremental current steps $(0.1 \mathrm{~ms}, 10-50 \mu \mathrm{A})$ was applied by a stimulus isolator (Iso-Flex, AMPI) to the extracellular electrode in L1. Finally, gabazine $(10 \mu \mathrm{M})$ was added to the ACSF and recordings of the sEPSC, sIPSCs, and ePSCs were repeated. At the end of experiments, slices were fixed in $4 \%$ paraformaldehyde (PFA) and processed, as previously published (Ohana et al., 2012), to reveal the biocytin in the recorded neurons. Stained neurons were carefully examined at the light microscope and their dendritic morphology and laminar and regional locations were noted. Only neurons with typical pyramidal morphology in L5 were selected for analysis (van Aerde and Feldmeyer, 2015). Few neurons were 3-dimensionally reconstructed at a $40 \times$ magnification with the Neurolucida system (MBF Bioscience).

Data analysis: for sEPSC and sIPSC analysis, current traces were filtered off-line at $1 \mathrm{kHz}$ and sEPSCs and sIPSCs were detected automatically in Clampfit at a threshold of -5 and $5 \mathrm{pA}$, respectively. All events were visually inspected by the experimenter. Traces of PSCs evoked by repeated stimuli (3-6 per stimulus intensity) were baseline subtracted and averaged. At each stimulus intensity, the averaged eEPSC trace evoked under gabazine was subtracted from the ePSC trace recorded under control ACSF to obtain a hypothetical evoked IPSC trace (eIPSC). The charge was calculated from the averaged ePSC, eEPSC, and eIPSC traces by integrating the current over an identical time window beginning $3 \mathrm{~ms}$ after stimulus and ending when the longer trace returned to baseline. The excitation/inhibition (E/I) ratio of the network was calculated by dividing the eEPSC charge carried by eIPSC. Experiments were included in the analysis, which contained a complete series of ePSC recordings at all current steps between 15 and $50 \mu \mathrm{A}$ (see Fig. $3 D, E$ ) in both ACSF and gabazine.

Adolescent social isolation. WT and Arc/Arg3.1 KO mice were socially isolated by individual housing from P35 and onward. Behavioral tests were conducted when the mice were 3 months old (Niwa et al., 2013; Li et al., 2018).

Sociability and social novelty tests. This test was done in a threechambered arena made of transparent Plexiglas $(20 \times 38.5 \mathrm{~cm}$ for the left and right side chambers, $12 \times 38.5 \mathrm{~cm}$ for the middle chamber). Plexiglas walls separated the three chambers, which were connected by open doors in the walls. Two transparent plastic cylinders with holes were placed in the left and right chamber. During the habituation phase, each mouse was released in the middle chamber and allowed to explore the arena for 10 min every day for $2 \mathrm{~d}$. In the sociability test, a Dummy Lego mouse and Novel Mouse 1 were placed underneath a plastic cylinder separately. A weighted object was placed on top to prevent the mice from climbing to the top or toppling the cylinder. The test mice were placed into the middle chamber for $10 \mathrm{~min}$ of free exploration. Two zones, centered on either cylinder with a radius $1.5 \mathrm{~cm}$ larger than the cylinders were defined as the close interaction zones. The duration the test mouse spent within these zones and in each chamber was recorded. The location of the Dummy Lego mouse or Novel Mouse1 was pseudorandomized. Subsequently, the same test mouse was subjected to the social novelty test. In this test, the Dummy Lego mouse was replaced by Novel Mouse 2, and Novel Mouse 1 was kept in the same cylinder as in the sociability test. The test mouse was again released into the middle chamber and allowed to explore for another $10 \mathrm{~min}$. The duration the test mouse spent within the close interaction zones and duration spent in exploring the three chambers was recorded. All the novel mice used in the experiments are wild types with gender and genetic background the same as the test mice. Videos were recorded, and mice exploration behaviors were tracked with EthoVision XT (Noldus Information Technology). Ethanol (35\%) was used for cleaning the arena between subjects.

$Y$-maze continuous spontaneous alternation. The Y-maze apparatus consisted of three identical arms (length $\times$ width $\times$ height: $37.5 \times 7.5 \times$ $16 \mathrm{~cm}$ ) made of opaque beige Plexiglas and interconnected at $120^{\circ}$ from a central triangle. It was located in a room with diffuse lighting (40 lux in each arm). For each trial, mice were placed in one arm of the maze and allowed to explore freely for $5 \mathrm{~min}$ during which the number and sequence of arm entries were noted down. A total number of arm entries was used as a measure for activity. The number of alternations, defined as successive entries into each of the three arms as an overlapping triplet set was calculated. Percentage alternation scores were then computed as follows: spontaneous alternation $(\%)=[($ Number of alternations $) /($ Total number of arm entries -2$)] \times 100$.

Prepulse inhibition of the acoustic startle reflex. Prepulse inhibition (PPI) of the acoustic startle reflex was examined in two startle response systems (SR-LAB, San Diego Instruments). The test platform consisted of a transparent cylindrical mouse enclosure mounted on a Plexiglas base and an accelerometer sensor connected at the base. This was housed inside a sound-attenuating chamber containing a light source and a sound generation system that emitted continuous background white noise $(65 \mathrm{~dB})$ and the various acoustic stimuli used during the test session. Before testing, startle calibration, and chamber standardization was conducted by mounting an SR-LAB Standardization Unit (San Diego Instruments) onto the animal enclosures to attain a reasonable waveform response $(700 \pm 15 \mathrm{mV})$ and to ensure that a given baseline response was similar for both test chambers. 
The test session began by introducing the mice in the animal enclosures. Following a $5 \mathrm{~min}$ acclimation period, mice were first presented with six pulse-alone trials to habituate and stabilize their startle response. The animals were subsequently presented with 12 main blocks of trials, each comprising a mixture of 12 discrete trial types: pulse-alone trials, prepulse-plus-pulse trials, prepulse-alone trials, and trials in which no discrete stimulus other than constant background noise was presented. The discrete trial types within each block were presented in pseudorandom order with variable intertrial intervals ranging from 10 to $20 \mathrm{~s}$. All stimuli were in the form of white noise with a rise time of $\sim 1 \mathrm{~ms}$ presented against a constant background noise level of $65 \mathrm{~dB}$. Pulse stimuli were $40 \mathrm{~ms}$ in duration and $120 \mathrm{~dB}$ in intensity. Prepulse stimuli were 20 $\mathrm{ms}$ in duration and were $69,73,77,81$, or $85 \mathrm{~dB}$ in intensity. This corresponded to $+4,+8,+12,+16$, or $+20 \mathrm{~dB}$ units above background noise. There were, therefore, five possible combinations of prepulse-plus-pulse trials, for which a stimulus onset asynchrony of $100 \mathrm{~ms}$ between the two stimuli was used. The test session concluded with the presentation of six pulse-alone trials and lasted $\sim 48 \mathrm{~min}$.

Whole-body responses were transduced by the accelerometer sensor, digitized, and transmitted to a computer running the SR-LAB software. Startle reaction was analyzed by measuring the maximum ( $V \max )$ of the waveform response (from 0 to $65 \mathrm{~ms}$ ) to the stimulus for every trial. Percentage of PPI for each prepulse trial $(69,73,77,81$, or $85 \mathrm{~dB})$ was calculated according to the following formula: percentage PPI $=[($ mean startle response to pulse alone trials) - (mean startle response for prepulse-plus-pulse trials) $/($ mean startle response to pulse alone trials) $] \times$ 100.

Locomotor activity and amphetamine sensitivity test in the open field. Spontaneous exploration and locomotor activity were evaluated in an open-field arena $(50 \times 50 \times 50 \mathrm{~cm})$ constructed from opaque white forex plates. In this test, mice are allowed to freely explore the arena for $1 \mathrm{~h}$. Locomotor activity was video-recorded under dim indirect illumination ( 40 lux) by using EthoVision XT video-tracking program (Noldus Information Technology). To test the dopamine sensitivity, an independent group of mice was injected with D-amphetamine intraperitoneally (1.5-2.5 mg/kg body weight, Fagron). Locomotor activity was recorded for $10 \mathrm{~min}$ before injection and for $1 \mathrm{~h}$ after the injection. For all tests, the path length and velocity were analyzed. The arena was cleaned with $70 \%$ ethanol between subjects.

Immunofluorescence staining and confocal imaging. Adult mice were deeply anesthetized and transcardially perfused with $0.1 \mathrm{M}$ PBS followed by $4 \%$ PFA. Brains were removed, postfixed with $4 \%$ PFA for $2-6 \mathrm{~d}$, cryoprotected in $30 \%$ sucrose for $2 \mathrm{~d}$, embedded in Tissue-Tek OCT (Sakura, Finetek) and sectioned $(20 \mu \mathrm{m})$ on a cryostat (Hyrax C60, Microm). Free-floating sections were blocked with $10 \%$ horse serum, $0.2 \%$ bovine serum albumin (BSA), and $0.3 \%$ TritonX in PBS for $1 \mathrm{~h}$ and then incubated for $12 \mathrm{~h}(\mathrm{TH})$ or $48 \mathrm{~h}$ (synaptic proteins) in primary antibody solution containing $1 \%$ horse serum, $0.2 \%$ BSA, and $0.3 \%$ Triton X-100 in PBS. For synaptic clusters analysis, antibodies against the presynaptic marker synaptophysin were coapplied with antibodies against the postsynaptic scaffolding proteins PSD-95 (excitatory synapse marker) and gephyrin (inhibitory synapse marker). Primary antibodies used were as follows: mouse anti-TH monoclonal antibody (1:5000; IMMUNOSTAR, 22941), mouse anti-gephyrin (1:300; Synaptic Systems, 147 011), rabbit anti-PSD-95 (1:500; Invitrogen, 51-6900), guinea pig anti-synaptophysin 1 (1:1000; Synaptic Systems, 101004). Sections were subsequently incubated with fluorophore-conjugated secondary antibodies at room temperature for $2 \mathrm{~h}$. Secondary antibodies used were as follows: goat anti-mouse AlexaFluor 555 (1:1000; ThermoFisher, A-21422), goat antimouse DyLight 633 (1:200; ThermoFisher, 35513), goat anti-rabbit AlexaFluor 555 (1:200; ThermoFisher, A-21428), and goat anti-guinea pig AlexaFluor 488 (1:200; ThermoFisher, A-11073). Sections were then rinsed and mounted with ProLong Gold Antifade Mountant with DAPI (Invitrogen, P36931) and stored in the dark.

Brain sections were imaged with a confocal microscope (TCS SP8, Leica). For quantification of TH immunoreactivity, stacks of 15 images at $1 \mu \mathrm{m}$ increment steps were acquired at $20 \times$ magnification and a $1 \mathrm{AU}$ pinhole. Images were analyzed with FIJI blind to the genotypes. Images were background subtracted, and $Z$-projected to generate a summed- intensity image. The mean TH immunofluorescence was measured from regions-of-interest (ROIs) positioned over the striatum or PFC and normalized to the ROI area.

Synaptic clusters were quantified in the PrL and IL regions of the PFC from three WT and three KO mice. Three brain sections per mouse were taken at bregma coordinates 1.7-1.9. Non-overlapping image stacks (12 per mouse) were captured in the cell-sparse and dendrites-enriched L1, using a $63 \times 1.4 \mathrm{NA}$ oil-immersion objective and a $2.4 \times$ digital zoom with the pinhole set to $1 \mathrm{AU}$. Stacks of four consequent images were captured at $1024 \times 1024$ pixels and $0.25 \mu \mathrm{m} z$-steps increment, resulting in imaged region size of $76.88 \times 76.88 \times 1 \mu \mathrm{m}$ and a voxel size of $0.075 \times$ $0.075 \times 0.25 \mu \mathrm{m}$. Laser intensity, detector sensitivity and line averaging were optimized against sections stained with secondary antibodies only. Identical image acquisition parameters were applied to the sections of all mice. Image stacks were analyzed in Imaris 9.3 (Bitplane) using the Spot function and the MATLAB R2017 (MathWorks) extension for Spot colocalization. Images were background subtracted. Spots were automatically detected above a threshold of $0.2 \mu \mathrm{m}$ diameter for PSD-95 and gephyrin and $0.3 \mu \mathrm{m}$ for synaptophysin. Colocalization between synaptophysin and either gephyrin or PSD-95 spots was set at a maximal center-to-center distance of $0.7 \mu \mathrm{m}$.

Kainic acid-induced seizures. Mice were taken from their cages and received an intraperitoneal injection of $20 \mu \mathrm{g}$ kainic acid per gram body weight. From there on animals were monitored for seizure symptoms. Seizures were defined as having occurred when the animals showed typical symptoms of rearing with forelimb clonus, falling, and rotating. If animals did not show any of these symptoms within $30 \mathrm{~min}$, they were administered additional equal or lower dosages of kainic acid until seizures occurred. The seizure strength was scored by the following criteria: (1) Strong seizure activity like clonus of forelimbs and head, rearing but no falling; (2) as in 1, but additionally falling; (3) as in 2, but more severe with additional jumping, uncontrolled circling or repetitive falling. The final dose of kainic acid injected ( $\mu \mathrm{g} / \mathrm{g}$ body weight) was calculated from the sum of all injection volumes.

Electrocorticogram recording and analysis. Data were collected as previously described (Marguet et al., 2015). Telemetric electrocorticogram analyses were performed using implantable radio transmitters (models TA11EA-F20 or TA11ETA-F20, DataSciences International). Adult (at least 3 months old) male mice received $0.05 \mathrm{mg} / \mathrm{kg}$ buprenorphine (subcutaneously) for analgesia and were anesthetized with 1.5-2\% isoflurane in $100 \%$ oxygen. Midline skin incisions were made on the top of the skull and in the neck. The transmitter body was implanted subcutaneously. The tips of the leads were placed $2 \mathrm{~mm}$ posterior to bregma and $1.8 \mathrm{~mm}$ right to the midline for the recording electrode, and $1 \mathrm{~mm}$ posterior to lambda and 1-2 mm left to the midline for the reference electrode. The electrodes were fixed with dental cement. Radio transmitters allowed simultaneous monitoring of electrocorticogram and motor activity in undisturbed, freely moving mice that were housed in their home cages. Telemetry data and corresponding video data were recorded 1 week after surgery at the earliest and were stored digitally using Ponemah software v5.1 (Data Sciences International). Electrocorticogram recordings lasted over $50 \mathrm{~h}$, sampled at $500 \mathrm{~Hz}$, with continuous video recording. Electrocorticograms were analyzed off-line in MATLAB R2014b (MathWorks).

To find any ictal activity, we first tried to automatically detect the largest nonpathological electrocorticogram pattern available, namely $\mathrm{K}$-complexes. Detection settings for putative K-complexes were defined as having a positive and negative peak of at least $2 \times$ the amplitude of baseline activity, at least $15 \mathrm{~ms}$ in length each and where the end of a positive peak necessarily needed to be followed by the start of a negative peak within $15 \mathrm{~ms}$. An additional criterion was to restrict detection during slow-wave sleep. For this, the electrocorticogram was Butterworth filtered in the delta range $(0.5-3 \mathrm{~Hz}$, third order). The instantaneous delta amplitude (moving average filter, width $2 \mathrm{~s}$ ) at any putative K-complex needed to be $>95 \%$ of the mean instantaneous delta amplitude of the entire recording. Then, any event that exceeded twice the median peak-to-peak amplitude of these detected putative K-complexes was investigated for possible signs of ictal activity.

For automatic REM-like sleep detection, the electrocorticogram was Butterworth filtered in the following frequency ranges: delta $(0.5-3 \mathrm{~Hz}$, 


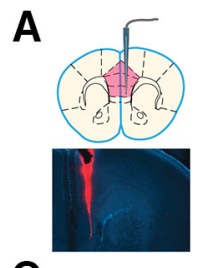

B
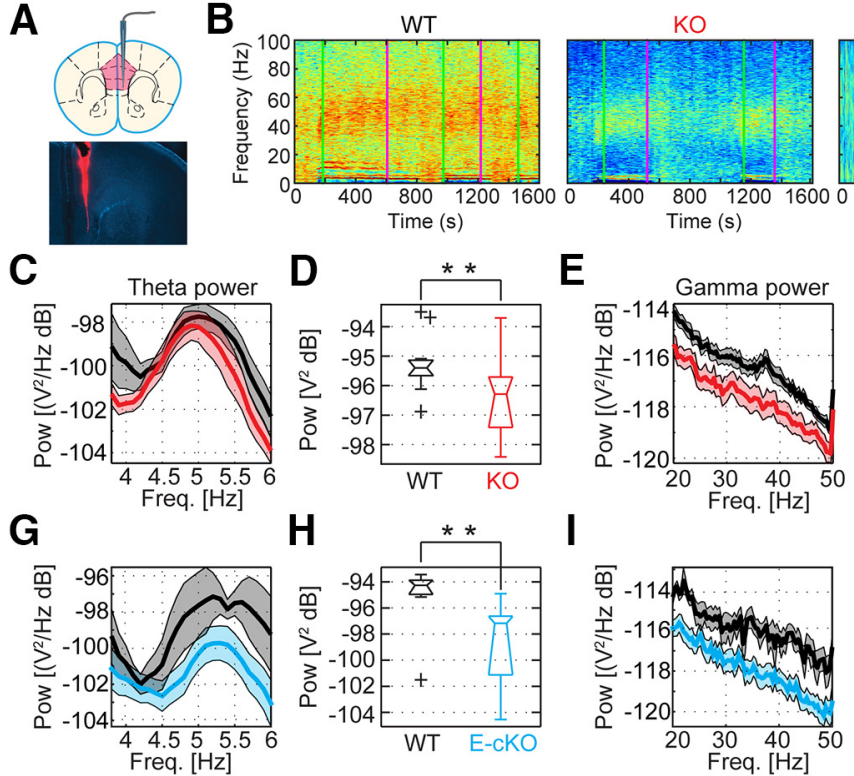

Figure 1. Genetic deletion of Arc/Arg3.1 prenatally or perinatally results in hypoactive PFC networks. A, Illustration of LFP recording in the PFC (top) and histological verification of Dil-coated probes (red) with DAPI staining shown in blue (bottom). $\boldsymbol{B}$, Spectrograms of exemplary excerpts of PFC activity for WT, KO, and E-cKO mice. $C, D$, Reduced theta power in the PFC of KO mice. $\boldsymbol{E}, \boldsymbol{F}$, Reduced gamma power in the PFC of KO mice. $\boldsymbol{G}, \boldsymbol{H}, \mathrm{E}-\mathrm{CKO}$ mice exhibit significantly reduced theta power in the PFC compared with their WT littermates. I, J, Significantly reduced gamma power in the PFC of E-CKO mice. Power spectra were calculated from the LFP during REM-like states. Means are plotted as continuous lines, and shades represent $\pm S E M$. In corresponding boxplots, hourglass markers represent the median, 25th and 75th percentiles. Crosses mark outliers. WT: $n=11, \mathrm{~K} 0: n=10$; WT: $n=7$, E-cKO: $n=10$. Mann-Whitney-Wilcoxon test was applied in $\boldsymbol{D}, \boldsymbol{F}, \boldsymbol{H}$, and $\boldsymbol{J}$ with ${ }^{*} p<0.05,{ }^{* *} p<0.01$.

third order), theta $(6-11 \mathrm{~Hz}$, third order), gamma $(50-90 \mathrm{~Hz}$, sixth order), and high frequency (150 high-pass, 14th order). The instantaneous amplitudes were further filtered with a moving average filter (width: $2 \mathrm{~s}$ ), from which a mean was calculated for each frequency band. Putative REM-like epochs needed to meet the following criteria: (1) exceed 65 and $70 \%$ of the mean theta and gamma amplitude, respectively; (2) be $<95$ and $120 \%$ of the mean delta and high-frequency amplitude, respectively; (3) show an absence of any detected movement activity; (4) exceed $7.5 \mathrm{~s}$ in length; and (5) be $<120 \%$ of the mean highfrequency amplitude $2 \mathrm{~min}$ before the putative REM-like epoch. Gaps between detected REM-like epochs $<5 \mathrm{~s}$ in length were still determined to be part of a REM epoch. Putative REM-like epochs that were still detected in between bouts of activity were deemed false positives and excluded. One power spectrum per mouse was calculated from concatenated epochs $(\mathrm{nFFT}=4096, \mathrm{nw}=1)$ and normalized for the full range of $0-250 \mathrm{~Hz}$.

Radioactive in situ hybridization. Sagittal brain slices $(14 \mu \mathrm{m})$ were prepared using a cryostat and mounted on slides (Superfrost plus, ThermoFisher Scientific). In situ hybridization was performed as described before (Hermey et al., 2013). A fragment corresponding to nucleotides 2342-2923 of the Arc/Arg3.1 three prime untranslated region ( $3^{\prime}$ UTR) was used as a probe and specificity of signals was verified by comparing with KO. Probes labeled with $\left[\alpha^{-}{ }^{35} \mathrm{~S}\right]-\mathrm{UTP}$ were generated according to the manufacturer's instructions (Promega). Transcribed probes were cleaned using G-50 mini columns (GE Healthcare) and diluted in hybridization buffer $(4 \times$ SSC, $50 \%$ formamide, $1 \mathrm{~m}$ Denhardt's solution, $10 \%$ dextran sulfate, $0.5 \mathrm{mg} / \mathrm{ml}$ salmon sperm DNA, $0.25 \mathrm{mg} / \mathrm{ml}$ yeast t-RNA) to a concentration of $5000 \mathrm{cpm} / \mu \mathrm{l}$. Mounted cryosections of brains were fixed in $4 \%$ PFA, acetylated, dehydrated, and hybridized at $55^{\circ} \mathrm{C}$ overnight. Ribonuclease A treatment was performed for $30 \mathrm{~min}$ at $37^{\circ} \mathrm{C}$. Following a high stringency wash in $0.1 \times$ saline sodium citrate buffer at $55^{\circ} \mathrm{C}$, slides were exposed to X-ray films (Kodak Biomax MR; GE Healthcare Bioscience).

Immunoblotting. Cortical tissues were dissected and quick-frozen on dry ice and stored at $-80^{\circ} \mathrm{C}$ until used. Dissected tissue was homogenized in lysis buffer containing 5 mм EDTA, 5 mм EGTA, 50 mм NaF, 1
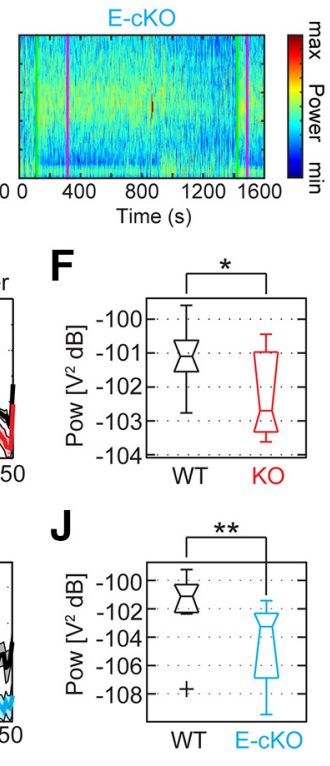

$\mathrm{mm} \mathrm{Na}_{3} \mathrm{VO}_{4}, 1 \%$ Triton X-100, 1 mm PMSF, 4 $\mu \mathrm{g} / \mathrm{ml}$ aprotinin, $1 \mu \mathrm{g} / \mathrm{ml}$ leupeptin, and 200 $\mathrm{ng} / \mathrm{ml}$ pepstatin A in PBS. Protein concentrations were determined using BCA assay (ThermoFisher, Pierce). Equal amounts of protein were electrophoresed on 12\% SDS polyacrylamide gels and transferred to PVDF membranes. Western blots were blocked in 5\% nonfat milk in PBS with $0.01 \%$ Tween and incubated overnight with a polyclonal anti-Arc/ Arg3.1 antibody (1:300,000; Synaptic Systems) or monoclonal anti-GAPDH antibody (1: 500,000; Millipore). After secondary antibody incubation, bands were visualized using SuperSignal chemiluminescence reagent (ThermoFisher, Pierce). Immunopositive bands were detected by ImageQuant LAS 4000 (Fujifilm) and analyzed using ImageJ (NIH).

Experimental design and statistical analysis. Statistical tests used were as follows: two-tailed two-sample Student's $t$ test, Mann-WhitneyWilcoxon test, Kolmogorov-Smirnov test, two-way ANOVA with repeated measures and Bonferroni post hoc test. Type of test is indicated in the main text. Statistics were done with SPSS Statistics 19 (IBM) and OriginPro 2017 (OriginLab); $p<0.05$ was considered as significant. All graphs were generated with OriginPro 2017, Igor Pro 6.3 (WaveMetrics), Adobe Illustrator CS5.5, and MATLAB R2014b/R2017b (MathWorks). Values presented in figures are mean \pm SEM or median with 25 th and 75 th percentile, as indicated.

\section{Results}

Deletion of $\operatorname{Arc/Arg3.1}$ before but not during puberty results in reduced prefrontal network activity

Schizophrenia is widely considered a neurodevelopmental disease, caused by combined genetic deficits and environmental assaults inflicted during brain development (Rapoport et al., 2012; Birnbaum and Weinberger, 2017). Disrupted brain development often results in aberrant brain activity preceding disease onset and psychosis (Lisman, 2012; Uhlhaas and Singer, 2015; Hunt et al., 2017). This aberrant activity is particularly evident in the prefrontal cortex, a region implicated in schizophrenia pathology.

To examine whether genetic deletion of Arc/Arg3.1 might affect network activity, we performed LFP recordings from the PFC of urethane-anesthetized WT and KO mice (Fig. 1A). LFP recordings during REM-like episodes revealed a significant loss of power in the theta (Mann-Whitney-Wilcoxon test, $U=20,{ }^{* *} p=$ 0.0076 , WT: $n=11, \mathrm{KO}: n=10$; Fig. $1 B-D)$ and gamma $(U=20$, ${ }^{*} p=0.022$; Fig. $\left.1 B, E, F\right)$ bands in $\mathrm{KO}$ mice.

To investigate whether the reduced network activity reflects a developmental effect of $\operatorname{Arc} / \operatorname{Arg} 3.1$, we first bred the Arc/Arg3. $1^{\text {f/f }}$ mice with CaMKII $\alpha$-Cre mice (Casanova et al., 2001). The progeny of this breeding are cKO mice in which $\mathrm{Arc} / \mathrm{Arg} 3.1$ is irreversibly removed between P7 and 14 (Gao et al., 2018). We named these mice early-cKO. Remarkably, like KO mice, adult earlycKO mice also displayed significantly reduced theta $(U=68$, ${ }^{* *} p=0.00758$, WT: $n=7$, E-cKO: $n=10$; Fig. $\left.1 B, G, H\right)$ and gamma $\left(U=64,{ }^{* *} p=0.0027\right.$; Fig. $\left.1 B, I, J\right)$ power in the PFC compared with their WT littermates.

We further assessed the effects of Arc/Arg3.1 ablation during puberty, on network activity by using a second line of conditional Arc/Arg3.1 KO mice in which Arc/Arg3.1 was genetically deleted through CaMKII $\alpha$-Cre-mediated recombination starting at P21 
and completing $\sim$ P36 (Fig. $2 A-C$; Gao et al., 2018). The progeny of this breeding were named late-cKO mice. In contrast to the constitutive $\mathrm{KO}$ and early-cKO, LFP recordings in the PFC of late-cKO mice exhibited normal theta and gamma power, indistinguishable from their WT littermates (theta: $U=64, p=0.154$, gamma: $U=63, p=0.172$, WT: $n=10$, L-cKO: $n=10$; Fig. $2 D-H$ ). Compared with all WT and WT-controls pooled together, KO mice exhibited significantly reduced theta and gamma power $(p<$ $0.05)$, whereas late-cKO exhibited unchanged gamma and theta power $(p>$ 0.05).

Collectively, these findings show that expression of Arc/Arg3.1 during early brain development is crucial for establishing normal oscillatory network activity in the PFC. Later deletion of Arc/Arg3.1 had no overt effect on network activity in the PFC, similar to our findings in the hippocampus (Gao et al., 2018).

\section{Altered excitatory and inhibitory synaptic transmission in the PFC of KO mice}

Alterations in the function, size, or numbers of excitatory and inhibitory synapses affect network oscillations (Buzsáki and Wang, 2012) and are linked to schizophrenia and other neuropsychiatric disorders (Uhlhaas and Singer, 2015). To elucidate synaptic mechanisms underlying altered network oscillations in the KO mice we recorded spontaneous and evoked synaptic currents from L5 pyramidal neurons in PFC slices obtained from WT and KO mice (Fig. $3 A, B$ ).

To measure the strength and temporal overlap of excitation and inhibition, we recorded ePSCs in ACSF and the presence of the type A GABA $\left(\mathrm{GABA}_{\mathrm{A}}\right)$ receptor antagonist gabazine. Example current traces recorded in WT and $\mathrm{KO}$ neurons are shown in Figure 3C. In the presence of gabazine, eEPSCs increased in amplitude and duration and displayed additional delayed peaks, indicative of recurrent excitation. Accordingly, the differential trace (eEPSC subtracted from ePSC; Fig. 3C) reflects predominantly the recurrent inhibitory current (eIPSC). As exemplified in Figure 3C, eEPSCs and eIPSCs in WT neurons were often much larger compared with $\mathrm{KO}$ neurons, although ePSCs recorded in ACSF were comparable. The mean net charge transferred by coactive excitatory and inhibitory synapses (Fig. 3D) increased gradually in both WT and KO neurons and was not significantly different between them (two-way ANOVA with repeated measures, genotype: $F_{(1,10)}=0.53, p=0.48$; intensity: $F_{(4,40)}=1.47, p=0.23$; interaction: $\left.F_{(4,40)}=0.83, p=0.52\right)$. In
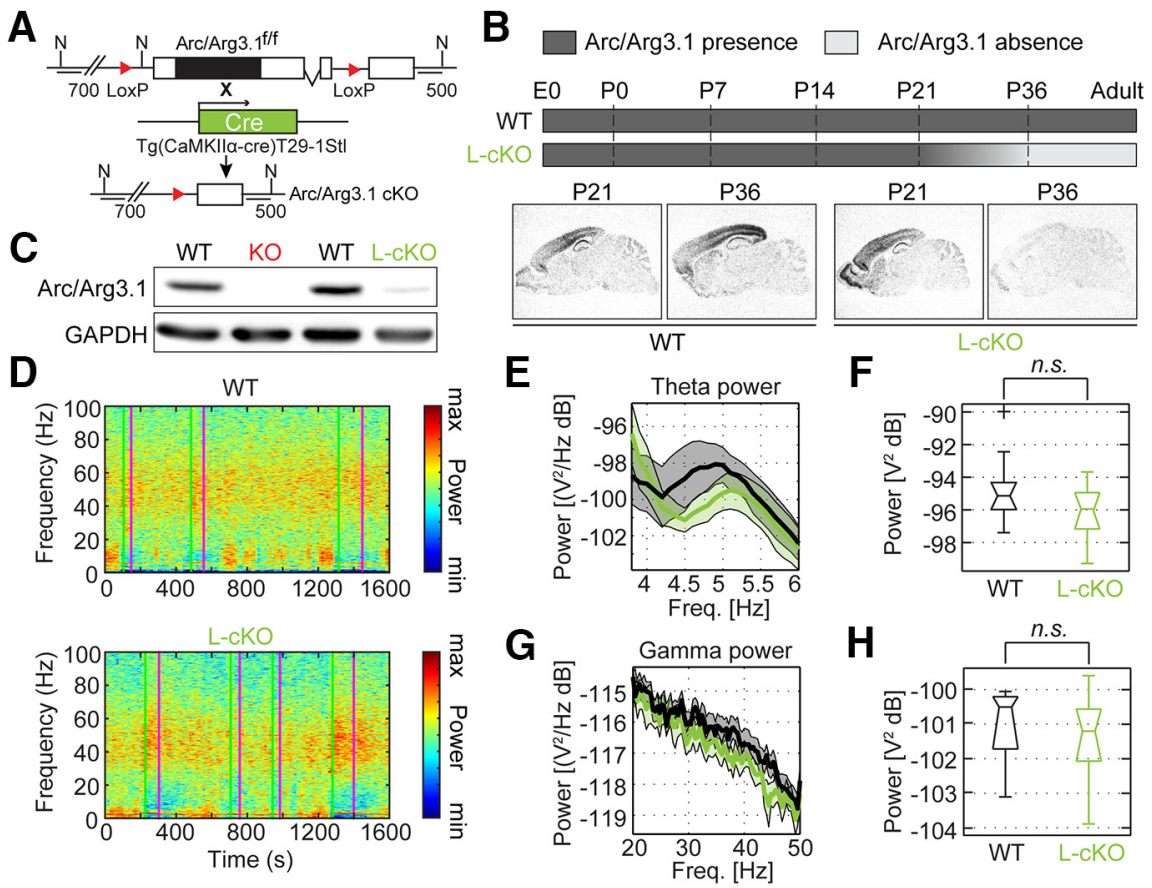

Figure 2. Conditional deletion of $\operatorname{Arc} / \operatorname{Arg} 3.1$ late in development does not alter PFC network activity. $A, A r c / A r g 3.1^{f / f}$ mice were bred with Cre recombinase carrying mice to generate L-cKO mice. B, Radioactive in situ hybridization with Arc/Arg3.1 antisense probe, performed on sagittal sections of WT and L-cKO brains. Ablation of Arc/Arg3. 1 takes place between P21 and P36 in CK0 mice. C, Representative Western blots of Arc/Arg3.1 protein from the dissected cerebral cortex of adult WT, K0, and L-cKO mice. D, Spectrograms of exemplary excerpts of PFC activity for WT and L-cKO mice. $\boldsymbol{E}, \boldsymbol{F}$, Comparable theta power in WT and L-cKO mice. $\boldsymbol{G}$, $\boldsymbol{H}$, Indistinguishable gamma power in WT and L-cKO mice. Power spectra were calculated from the LFP during REM-like states. Means are plotted as continuous lines and shades represent \pm SEM. In corresponding boxplots, hourglass markers represent the median, 25 th and 75 th percentiles. Crosses mark outliers. WT: $n=10, \mathrm{~L}-\mathrm{CK} 0: n=10$. Mann-Whitney-Wilcoxon test was applied in $\boldsymbol{F}$ and $\boldsymbol{H}$; n.s., not significant.
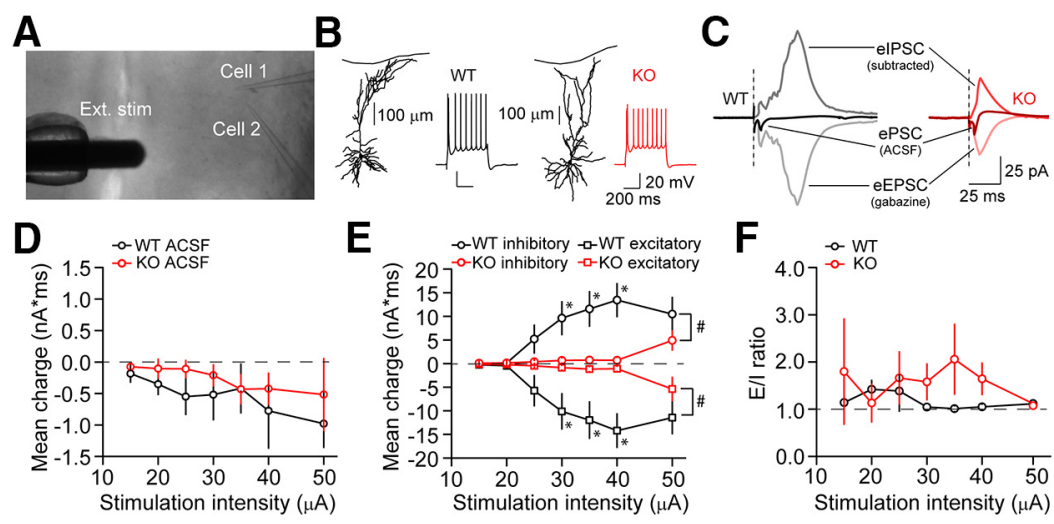

Figure 3. Reduced recurrent excitatory and inhibitory synaptic currents in PFC slices from KO mice. $A$, Image of a patch-clamp recording from $L 5$ neurons in a PFC slice with an extracellular stimulation electrode placed in L1. B, Examples of biocytin-filled and reconstructed WT and KO neurons with similar dendritic morphology and burst firing patterns. C, Examples of evoked PSC recorded in ACSF and gabazine and the subtracted elPSC trace. Stimulus intensity was $50 \mu \mathrm{A}$. Stimulus artifacts were replaced by dashed lines. $\boldsymbol{D}$, The mean net charge during the ePSC (ACSF) was similar in WT and KO neurons. $\boldsymbol{E}$, The mean excitatory and inhibitory charges were significantly larger in WT neurons compared with $K O$. $\boldsymbol{F}$, The E/I charge ratio was not different between WT and KO neurons. Two-way ANOVA with repeated measures was applied in $\boldsymbol{D}-\boldsymbol{F}$. Symbols show mean $\pm S E M ; n=6$ neurons from 3 mice per group; main genotype effect, $\# p<0.05$; Bonferroni post hoc, ${ }^{*} p<0.05$.

contrast, the mean excitatory and inhibitory charges increased abruptly at stimuli $>20 \mu \mathrm{A}$ (WT) and $40 \mu \mathrm{A}$ (KO; Fig. 3E), and were significantly larger in the WT neurons (excitatory charge: two-way ANOVA with repeated measures, genotype: $F_{(1,10)}=$ $5.93, \# p=0.035$; intensity: $F_{(4,40)}=6.79, p<0.001$; interaction: $F_{(4,40)}=4.96, p=0.002$; Bonferroni post hoc, ${ }^{\star} p=0.038,0.022$, 

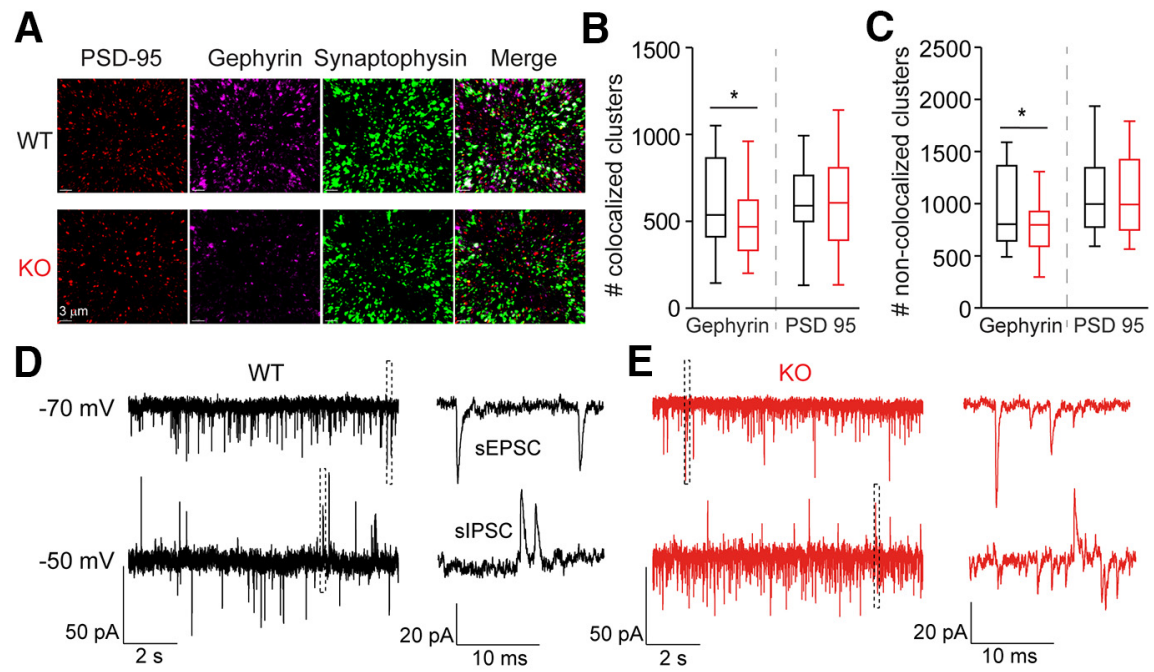

E
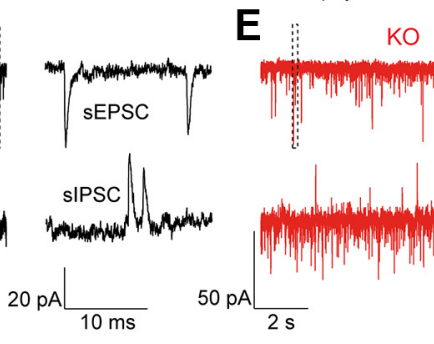

G
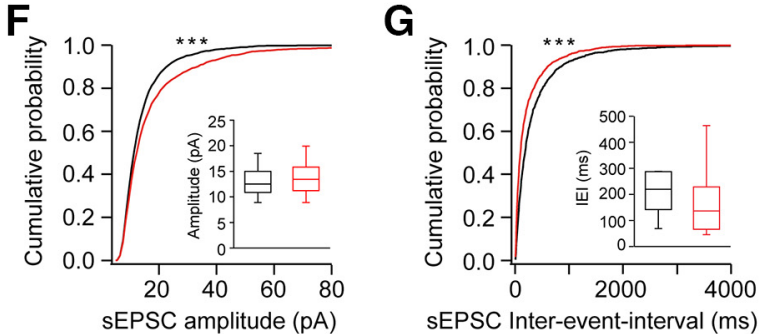

H

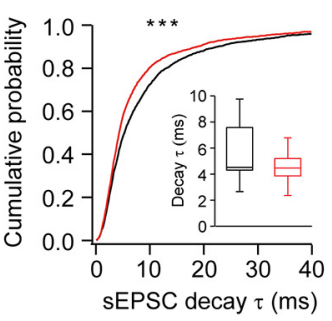

$\mathrm{J}$

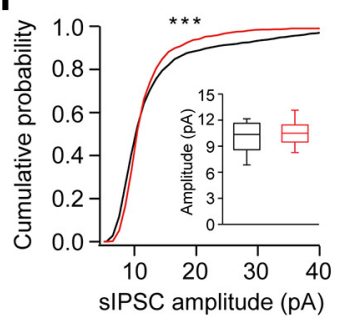

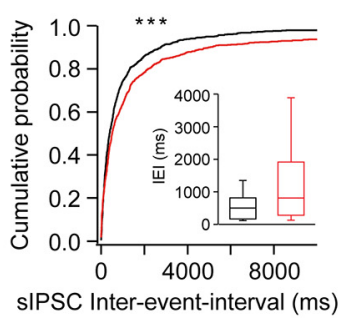

We, therefore, first examined the number of synapses in the PFC by immunolabeling of the presynaptic marker synaptophysin, the excitatory postsynaptic marker PSD-95 and the inhibitory postsynaptic protein gephyrin (Fig. 4A). Labeling revealed a significant reduction in colocalized (Fig. 4B) and non-colocalized (Fig. 4C) gephyrin clusters in the KO PFC sections (unpaired two-tailed $t$ test, colocalized: $t_{(70)}=2.06,{ }^{\star} p=0.043, n=36$ ROIs, 3 mice per group; non-colocalized: $t_{(70)}=2.01,{ }^{*} p=0.047, n=36$ ROIs, 3 mice per group) without a change in the number of PSD-95 clusters (unpaired twotailed $t$ test, colocalized: $t_{(70)}=0.18, p=$ $0.86, n=36$ ROIs, 3 mice per group; noncolocalized: $t_{(70)}=0.013, p=0.99, n=36$ ROIs, 3 mice per group; Fig. $4 A-C$ ).

Next, we analyzed sEPSCs recorded at $-70 \mathrm{mV}$ (Fig. $4 D, E$, top traces) and sIPSCs at $-50 \mathrm{mV}$ (Fig. $4 D, E$, bottom traces). Example traces show a highfrequency of sEPSCs and a lower frequency of sIPSC in both WT and KO neurons (Fig. 4D,E). Cumulative histograms show differences between WT and KO sEPSCs only at the right tail of the distributions, indicating the presence of more events with larger amplitudes (Kolmogorov-Smirnov test, ${ }^{* * *} p<$ 0.001; Fig. $4 F$ ), shorter inter-event intervals (IEIs; Kolmogorov-Smirnov test, ${ }^{* * *} p<0.001$; Fig. $4 G$ ) and faster decay time constants (Kolmogorov-Smirnov test, ${ }^{* *} p<0.001$; Fig. $4 H$ ) in the KO neurons. The median values per neuron were not different between WT and KO for any of the measured properties (unpaired two-tailed $t$ test, amplitude: $t_{(21)}=$ $-0.99, p=0.33$, IEI: $t_{(21)}=1.30, p=0.21$, decay $\tau: t_{(21)}=1.60, p=0.13$; WT: $n=11$, KO: $n=12$; Fig. $4 F-H$, insets). Comparisons of the sIPSCs amplitude and IEIs between WT and KO neurons indicated fewer events with large amplitudes (KolmogorovSmirnov test, ${ }^{* * *} p<0.001$; Fig. $4 I$ ) and lon0.019; inhibitory charge: two-way ANOVA with repeated measures, genotype: $F_{(1,10)}=6.48, \# p=0.029$; intensity: $F_{(4,40)}=$ $6.69, p<0.001$; interaction: $F_{(4,40)}=5.34, p=0.002$; Bonferroni post hoc, $\left.{ }^{\star} p=0.033,0.018,0.019\right)$. Between 25 and $40 \mu \mathrm{A}$, the mean excitatory and inhibitory charges in WT were $\sim 10$ - and 7 -fold larger than in $\mathrm{KO}$ neuron, respectively. However, the ratio between the excitatory and inhibitory charges (E/I ratio; Fig. $3 F$ ) was similar in WT and KO neurons (two-way ANOVA with repeated measures, genotype: $F_{(1,10)}=0.68, p=0.43$; intensity: $F_{(4,40)}=0.18, p=0.95$; interaction: $\left.F_{(4,40)}=0.77, p=0.55\right)$. These data indicate that the excitatory recurrent network gain is reduced in PFC slices of $\mathrm{KO}$ mice, but the $\mathrm{E} / \mathrm{I}$ balance is preserved. Reduced network gain in the KO slices can be the consequence of decreased synapse numbers, altered synaptic properties, or reduced rates of specific recurrent connections within the network. ger IEIs (Kolmogorov-Smirnov test, ${ }^{* *} p<0.001$; Fig. $4 J$ ) in the KO neurons but equal median values in the WT and KO neurons (unpaired two-tailed $t$ test, amplitude: $t_{(21)}=0.86, p=0.39$, IEI: $t_{(21)}=$ $-0.36, p=0.72$; WT: $n=12$, KO: $n=11$; Fig. $4 I$, J, insets). In contrast, the decay time was significantly shorter over the entire distribution of sIPSCs in the KO neurons (Kolmogorov-Smirnov test, ${ }^{* *} p<0.001$; Fig. $4 K$ ). Accordingly, the median values of the sIPSC decay $\tau$ were significantly reduced compared with the WT (unpaired two-tailed $t$ test, decay $\tau: t_{(21)}=2.39,{ }^{*} p=0.026$; Fig. $4 K$, inset). Together, these data suggest that the majority of excitatory synapses onto PFC L5 neurons have similar properties in WT and KO mice. In contrast, $\mathrm{KO}$ inhibitory synapses have distinctly faster kinetics.

The reduced PFC activity in the KO mice might result in schizophrenia-like behavior. To test this possibility, we subjected both WT and KO mice to a battery of behavioral benchmark tests of schizophrenia. 
Prenatal ablation of $\mathrm{Arc} / \mathrm{Arg} 3.1$ does not affect social behaviors in adult mice Patients with schizophrenia frequently display abnormal social behaviors, typically expressed by reduced social engagement (Owen et al., 2016). We, therefore, tested Arc/Arg3.1 KO mice in a threechamber social interaction arena. During the habituation phase, mice were released into the central chamber and allowed to explore the arena for $10 \mathrm{~min}$ per day for 2 consecutive days (Fig. 5A). The time spent in each chamber was measured. Mice preferred to explore the two chambers with cylinders and spent comparable time in each chamber (time in chambers left vs right, paired two-tailed $t$ test, WT: $t_{(8)}=$ $-0.75, p=0.47, n=9$; KO: $t_{(8)}=-0.33$, $p=0.75, n=9$; Fig. $5 B$ ) with no difference between WT and KO mice, suggesting unbiased place exploration. To test the sociability, a dummy mouse made from Lego (Dummy Mouse) and an unfamiliar mouse (Novel Mouse 1) were placed into the cylinders in the left and right chamber, respectively (Fig. 5A). The test mouse was then free to explore all the chambers. Normal sociability is indicated by a clear preference to interact with the unfamiliar mouse (Novel Mouse 1) rather than the object (Dummy Mouse). Analysis of the close interaction time measured as time spent in the immediate vicinity of the chamber confirmed that both WT and KO mice preferably interacted with an unfamiliar living mouse rather than an object (close interaction time Dummy Mouse vs Novel Mouse 1, paired twotailed $t$ test, WT: $t_{(8)}=-6.43,{ }^{* * *} p=$ 0.0002 ; KO: $t_{(8)}=-5.43,{ }^{* * *} p=0.00062$; Fig. $5 C$ ). No genotype difference was observed in this test (close interaction time with Novel Mouse 1 WT vs KO, unpaired two-tailed $t$ test, $t_{(16)}=1.44, p=0.17$ ), indicating normal sociability for $\mathrm{KO}$ mice. To assess whether mice could distinguish a newly introduced mouse from a previously encountered mouse, mice were subjected to social novelty test in which the Dummy Mouse was replaced with a second stranger mouse (Novel Mouse 2; Fig. $5 A$ ). Proper recognition is indicated by preference to the second novel mouse. Again, WT and also KO mice spent significantly more time interacting with the Novel Mouse 2 (close interaction time Novel Mouse 1 vs Novel Mouse 2, paired two-tailed $t$ test, WT: $t_{(8)}=-2.61,{ }^{*} p=0.03 ; \mathrm{KO}: t_{(8)}=$ $-4.40,{ }^{* *} p=0.0023$; Fig. $\left.5 D\right)$, suggesting a comparable and intact social recognition ability (close interaction time with Novel Mouse $2 \mathrm{WT}$ vs KO, unpaired two-tailed $t$ test, $t_{(16)}=-0.11, p=$ 0.92; Fig. $5 D$ ). Notably, because the social recognition test was held $10 \mathrm{~min}$ after the sociability test, these data also demonstrate intact short-term memory for the Arc/Arg3.1 KO mice, in agreement with our previous report (Plath et al., 2006).

A

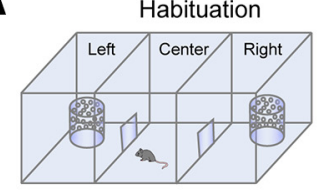

B

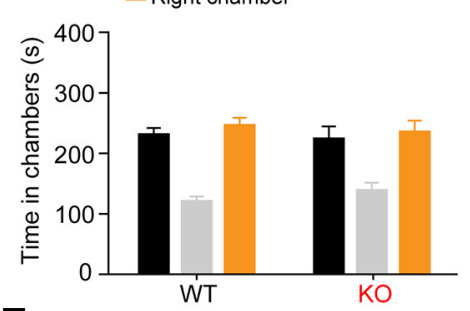

E

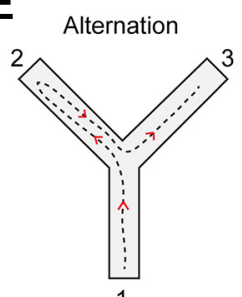

H
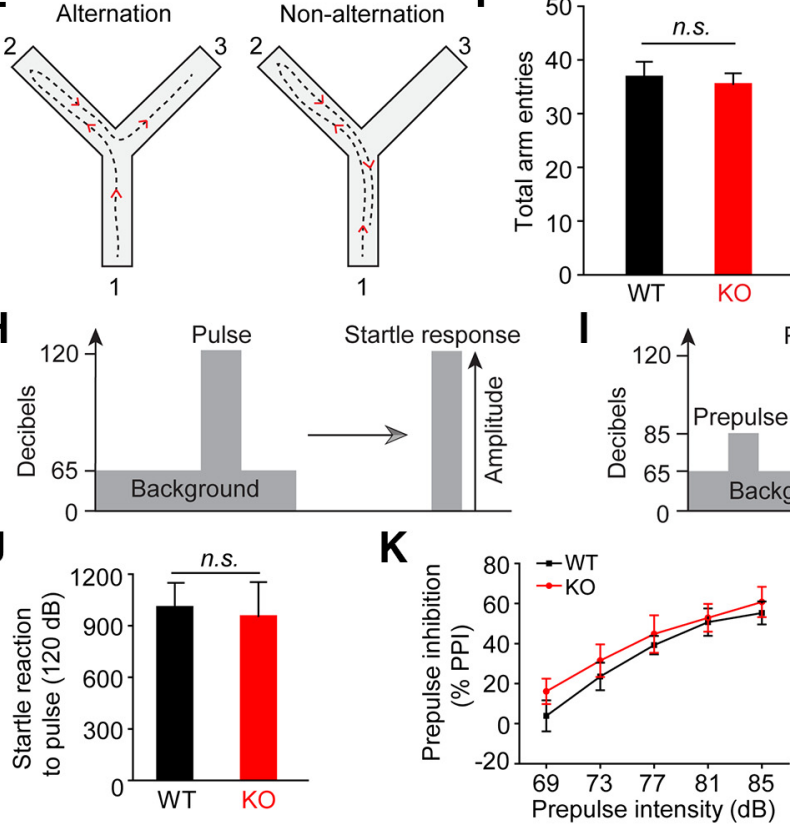

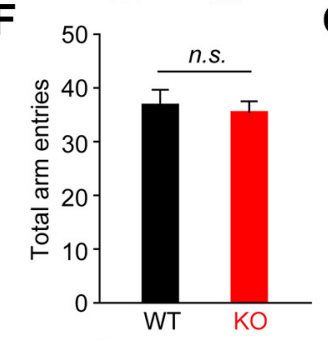

Social novelty test

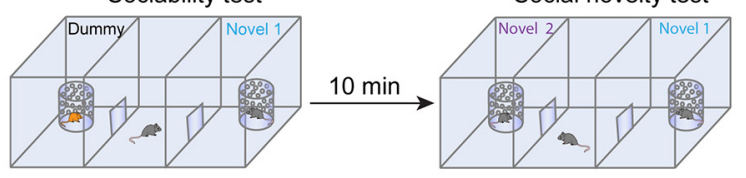

D

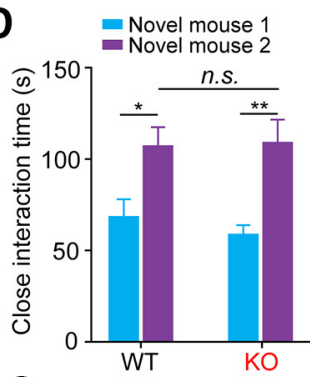

G

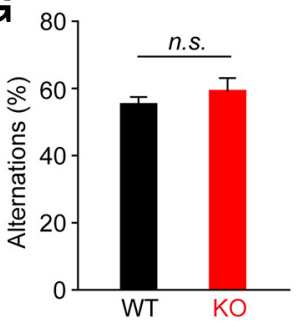

Figure 5. Prenatal ablation of Arc/Arg3.1 does not cause deficits in social engagement, working memory, or sensorimotor gating in adult mice. $\boldsymbol{A}$, Illustration of habituation, sociability, and social novelty tests in the social interaction arena. $\boldsymbol{B}$, WT and K0 mice spent a comparable amount of time exploring the two chambers with the cylinder, with no place bias during the habituation phase. C, Both WT and KO mice preferably interacted with the Novel Mouse 1 over the Dummy Mouse during the sociability test. $\boldsymbol{D}$, Both WT and KO mice preferably interacted with Novel Mouse 2 over Novel Mouse 1 during the social novelty test. All WT: $n=9$, KO: $n=9$. $\boldsymbol{E}$, Illustration of Y-maze test. Visiting of arms in order 1-2-3 is an example of alternation, whereas 1-2-1 of nonalternation. $\boldsymbol{F}$, Similar number of total arm entries in WT and KO mice. $\mathbf{G}$, WT and KO mice made comparable percentage of spontaneous alternations. All WT: $n=10, \mathrm{~K} 0: n=10$. $\boldsymbol{H}$, Illustration of startle response to $120 \mathrm{~dB}$ auditory stimulation. $\boldsymbol{I}$, Illustration of prepulse inhibition test. J, Strong startle responses were observed in both WT and K0 mice upon $120 \mathrm{~dB}$ stimulation. $\boldsymbol{K}$, Comparable PPI in WT and KO mice at various prepulse intensities. $\boldsymbol{L}$, No difference of mean percentage of PPI in WT and KO mice. All WT: $n=10, \mathrm{KO}: n=10$. Significance was tested with paired $t$ test within groups and two-tailed two-sample $t$ test between groups in $\boldsymbol{B}-\boldsymbol{D}$. Two-tailed two-sample t test was performed in $\boldsymbol{F}, \boldsymbol{G}, \boldsymbol{J}$, and $\boldsymbol{L}$. Two-way ANOVA with repeated measures was applied in $\boldsymbol{K}$. Bars show mean \pm SEM; n.S., not significant, ${ }^{*} p<0.05,{ }^{* *} p<0.01,{ }^{* *} p<0.001$.

\section{Prenatal ablation of Arc/Arg3.1 does not cause a working memory deficit in adult mice}

Deficits in working memory observed in patients are considered a cognitive impairment in schizophrenia (Lett et al., 2014). Therefore, we assessed mice behavior in the Y maze, which is frequently used to test working memory in rodents (Dember and Fowler, 1958; Lalonde, 2002; Sanderson and Bannerman, 2012). In this test, mice are free to move on a three-armed maze and naturally alternate between recently visited arms to avoid visiting the same arm repeatedly. The percentage of spontaneous alternations serves as a proxy of working memory (Fig. 5E). WT and KO mice 
A

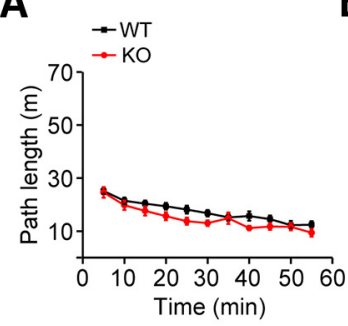

E $\rightarrow W T+A M P 2.5 \mathrm{mg} / \mathrm{kg} \quad \mathbf{F}$

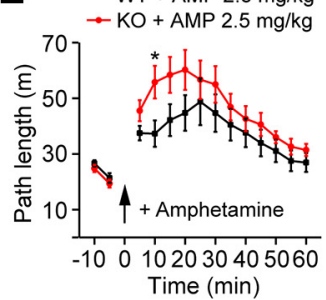

B
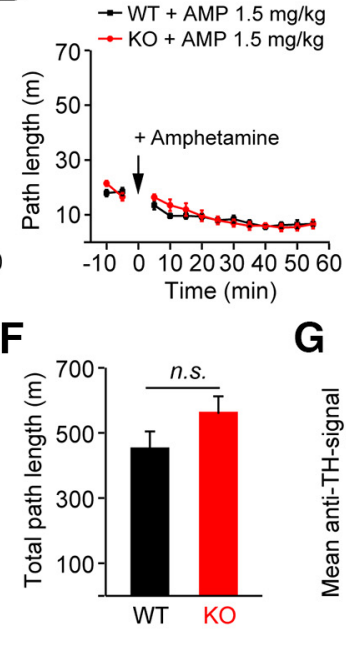

G
C
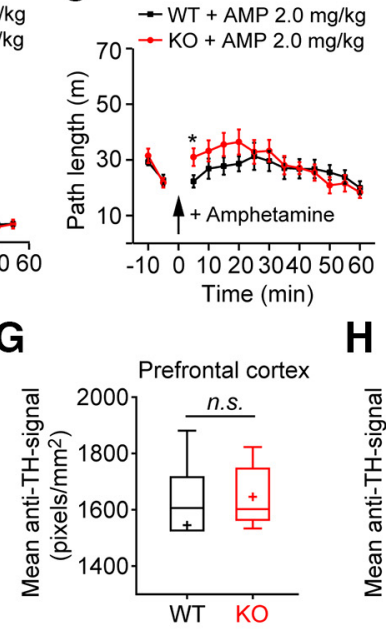

D

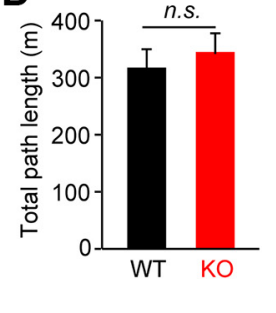

H

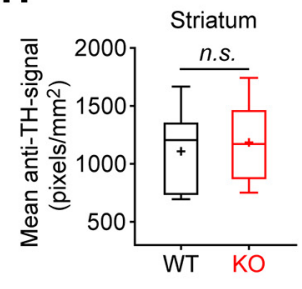

Figure 6. Prenatal ablation of Arc/Arg3.1 does not alter the spontaneous locomotor activity and dopaminergic innervation but transiently increases the response to amphetamine. $\boldsymbol{A}$, Spontaneous locomotor activity was comparable in WT and KO mice as indicated by total distance moved during $1 \mathrm{~h}$ open-field test (WT: $n=12$, K0: $n=8$ ). $\boldsymbol{B}-\boldsymbol{F}$, Locomotor activity following injection of amphetamine (AMP) at concentrations $1.5-2.5 \mathrm{mg} / \mathrm{kg}$ body weight. $\boldsymbol{B}$, Injection of $1.5 \mathrm{mg} / \mathrm{kg}$ amphetamine did not increase locomotion in either WT or KO mice. $\boldsymbol{C}$, Amphetamine at $2 \mathrm{mg} / \mathrm{kg}$ elicited a transiently increased locomotor activity in both WT and K0 mice, that was significantly higher in the K0 mice during the first $5 \mathrm{~min}$ (WT: $n=8, \mathrm{KO}: n=9$ ). $\boldsymbol{D}$, Comparable total path length in WT and $\mathrm{KO}$ mice during $1 \mathrm{~h}$ exploration after injection with $2 \mathrm{mg} / \mathrm{kg}$ amphetamine. $E$, Amphetamine at $2.5 \mathrm{mg} / \mathrm{kg}$ elicited a stronger but still transient increase of locomotion in WT and $\mathrm{KO}$ mice (WT $n=8, \mathrm{KO} n=9$ ). $\boldsymbol{F}$, Comparable total path length in WT and KO mice during 1 h exploration after injection with $2.5 \mathrm{mg} / \mathrm{kg}$ amphetamine. $\mathbf{G}, \boldsymbol{H}$, Quantification of TH-immunoreactivity shows comparable signal in (G) prefrontal cortex (WT: $n=12$ slices from 4 mice, K0: $n=11$ slices from 4 mice) and $(\boldsymbol{H})$ striatum of WT and K0 mice (WT: $n=12$ slices from 4 mice, K0: $n=12$ slices from 4 mice). Shown are mean \pm SEM $(\boldsymbol{A}-\boldsymbol{F})$, and median, 25 th and 75 th percentile, min and max value $(\boldsymbol{G}, \boldsymbol{H})$. Significance was tested with two-way AN0VA with repeated measures in $\boldsymbol{A}-\boldsymbol{C}$ and $\boldsymbol{E}$. Bonferroni post hoc was performed to test the difference between groups in $\boldsymbol{C}$ and $\mathbf{E} ;{ }^{*} p<0.05$. Significance was tested with two-tailed two-sample $t$ test between groups in $\boldsymbol{D}$ and $\boldsymbol{F}$ - $\boldsymbol{H}$; $\mathrm{n}$.S., not significant.

made similar numbers of arm entries (unpaired two-tailed $t$ test, WT vs KO: $t_{(18)}=0.41, p=0.69, n=10,10$, respectively; Fig. $5 F$ ), indicating a similar exploratory drive. WT and $\mathrm{KO}$ mice also exhibited a similar percentage of spontaneous alternations (unpaired two-tailed $t$ test, WT vs KO: $t_{(18)}=-0.91, p=0.37, n=$ 10,10 , respectively; Fig. $5 G$ ), indicating intact and indistinguishable performance in this working memory test.

\section{Prenatal ablation of $\mathrm{Arc} / \mathrm{Arg} 3.1$ does not affect sensorimotor gating ability in adult mice}

PPI of the acoustic startle response is frequently used to detect sensorimotor gating deficits linked to psychiatric disorders (Braff et al., 2001; Swerdlow et al., 2008). Schizophrenia patients reproducibly display reduced auditory PPI (Mena et al., 2016; Haß et al., 2017; Swerdlow et al., 2018). PPI has also been adapted for use on rodent models as a biomarker of schizophrenia-like phenotypes (Swerdlow et al., 2008). Given the effectiveness and sensitivity of this paradigm for schizophrenia phenotype screening, we assessed the degree of PPI for the Arc/Arg3.1 KO mice. In this test, an intense acoustic pulse alone leads to a strong startle response indicated by the peak amplitude of the whole-body acceleration measured by a piezoelectric sensor (Fig. $5 \mathrm{H}$ ). Both WT and $\mathrm{KO}$ mice generated strong startle responses to the pulse stimulus (120 $\mathrm{dB}$ ) with no difference between them, suggesting that $\mathrm{KO}$ mice had normal auditory perception like WT mice (unpaired twotailed $t$ test, WT vs KO: $t_{(18)}=0.22, p=0.83, n=10,10$, respectively; Fig. $5 J$ ). If a weaker pulse (henceforth the prepulse) is applied before the intense pulse, it leads to a reduced startle response (Fig. 5I). This inhibition effect produced by the prepulse presentation is termed PPI and reflects the sensorimotor gating ability of the mouse (Clapcote et al., 2007). Arc/Arg3.1 KO mice consistently showed PPI at different prepulse intensities (twoway ANOVA with repeated measures, genotype: $F_{(1,18)}=0.61$, $p=0.45$; prepulse intensity: $F_{(4,72)}=41.53, p<0.0001$; interaction: $F_{(4,72)}=0.38, p=0.82$; Fig. $\left.5 K\right)$ that were comparable to their WT littermates (unpaired two-tailed $t$ test, WT vs KO: $t_{(18)}$ $=-0.78, p=0.45, n=10,10$, respectively; Fig. $5 L$ ). These data indicate that the sensorimotor gating ability is not diminished in the $A r c / A r g 3.1 \mathrm{KO}$ mice.

\section{Prenatal ablation of $A r c / A r g 3.1$ does not alter spontaneous locomotor activity and only transiently increases the response to amphetamine \\ Additional biological traits identified in patients with schizo-} phrenia are locomotor anomalies (Sano et al., 2012) that are traced to hypersensitivity to dopaminergic stimulation (Seeman et al., 2005). To test spontaneous locomotor activity, we first subjected Arc/Arg3.1 WT and KO mice to a long-term open field test in which natural exploratory activity was recorded for $1 \mathrm{~h}$. No difference was observed between WT and $\mathrm{KO}$ mice as indicated by a similar path length (two-way ANOVA with repeated measures, genotype: $F_{(1,18)}=2.37, p=0.14$; time: $F_{(10,180)}=38.21$, $p<0.0001$; interaction: $F_{(10,180)}=1.36, p=0.20$, WT: $n=12$, KO: $n=8$; Fig. $6 A$ ) throughout the testing time, demonstrating that $\mathrm{KO}$ mice were neither hyperactive nor hypoactive. To test locomotor activity upon dopaminergic stimulation, we injected independent cohorts of mice with amphetamine $(1.5-2.5 \mathrm{mg} / \mathrm{kg}$ body weight, i.p.) to evoke dopamine release. Locomotor activity was recorded for $10 \mathrm{~min}$ before and $1 \mathrm{~h}$ after the injection. The lowest dose of amphetamine $(1.5 \mathrm{mg} / \mathrm{kg})$ did not elicit any increase of locomotion in neither WT nor KO mice (Fig. 6B). However, higher doses ( 2 and $2.5 \mathrm{mg} / \mathrm{kg}$ ) elicited a transient increase of locomotion in both genotypes, which was slightly stronger in the $\mathrm{KO}$ mice during the first 5 or $10 \mathrm{~min}$ after injection, respectively (genotype: $F_{(1,15)}=0.32, p=0.58$; time: $F_{(11,165)}=10.16$, $p<0.0001$; interaction: $F_{(11,165)}=2.84, p=0.002$, WT: $n=8$, 
KO: $n=9$; Fig. $6 C$; genotype: $F_{(1,15)}=$ 2.22, $p=0.16$; time: $F_{(11,165)}=15.24, p<$ 0.0001 ; interaction: $F_{(11,165)}=1.31, p=$ 0.23; Fig. 6E; Bonferroni post hoc test, ${ }^{\star} p<0.05$, WT: $n=8$, KO: $n=9$ ). However, no significant difference was detected in the total path length of WT and $\mathrm{KO}$ mice over the $1 \mathrm{~h}$ exploration after amphetamine injection (unpaired twotailed $t$ test, WT vs KO: $t_{(15)}=-0.57, p=$ 0.58; Fig. $6 D ; t_{(15)}=-1.49, p=0.16$; Fig. $6 F$ ). These data suggest that the spontaneous locomotor activity was not altered in the $A r c / A r g 3.1 \mathrm{KO}$ mice, and the sensitivity to amphetamine was only transiently increased.

Prenatal ablation of $\mathrm{Arc} / \mathrm{Arg3} .1$ does not disrupt dopaminergic innervation in the prefrontal cortex and the striatum To further investigate whether prenatal ablation of Arc/Arg3.1 could affect dopaminergic neurotransmission, we proceeded to directly measure dopaminergic innervation in the PFC (Fig. 6G) and striatum (Fig. 6H). We selected tyrosine hydroxylase, the enzyme for catalyzing dopamine synthesis as a marker, and performed immunofluorescent staining on both WT and KO slices. Dopaminergic fiber intensity was measured from confocal stack images. Interestingly, the dopamine axon density did not differ between WT and $\mathrm{KO}$ mice, neither in the prefrontal cortex (Mann-Whitney-Wilcoxon test, $U=75, p=0.61$, WT: $n=12$ slices from 4 mice, KO: $n=11$ slices from 4 mice; Fig. $6 G$ ) nor the striatum (Mann-Whitney-Wilcoxon test, $U=89, p=0.35$, WT: $n=12$ slices from 4 mice, $\mathrm{KO}$ : $n=12$ slices from 4 mice; Fig. $6 H$ ), suggesting unaltered dopaminergic projections in the absence of Arc/Arg3.1.

\section{Absence of epileptic brain activity and reduced seizure susceptibility in Arc/Arg3.1 KO mice}

Comorbidity of schizophrenia and epilepsy are common in humans and animal models (Clarke et al., 2012). To further investigate the possibility that aberrant neural activity and enhanced seizure susceptibility might increase the risk of developing schizophrenia-like phenotypes in the KO mice, we performed telemetric electrocorticogram recordings combined with videoand activity-monitoring in freely behaving WT and $\mathrm{KO}$ mice for a total duration of $50 \mathrm{~h}$ (Fig. $7 A-F)$. No behavioral abnormality, which could be associated with epileptic activity, was observed in any of the mice. Moreover, electrocorticograms from individual WT and KO mice (Fig. 7A) show similar patterns of electrographic activity. Notably, no continuous bands of low-frequency activity were observed in WT or KO mice, indicating the absence of epileptiform activity.

To investigate the possible occurrence of an inter-ictal activity, such as abnormally large single or multiple spikes in the electroencephalogram, we first detected putative K-complexes, which are large biphasic waves normally occurring in the cortex during sleep (Amzica and Steriade, 1997; Marini et al., 2004). Similar numbers of putative K-complexes were detected in WT and $\mathrm{KO}$ mice (Fig. $7 B-D$ ). No event, larger than the putative $\mathrm{K}$-complexes, which could reflect inter-ictal activity, was detected in any of the mice, confirming that both WT and KO mice were free of epileptiform or inter-ictal brain activity. We further analyzed REM-epochs of the recordings to detect possible abnormal activity during sleep. Power spectra of two WT and three KO mice all show expected theta and low- and high-gamma bands (Fig. 7 E, F). Moreover, KO mice did not show an additional pronounced peak at low frequencies $(1-30 \mathrm{~Hz})$, which is typical of epileptiform and ictal activity (Peters et al., 2005; Shin et al., 2008; Jefferys, 2010). We then examined the susceptibility of WT and KO mice to kainic acid-induced seizures. Surprisingly, a significantly higher dosage of kainic acid was required to evoke seizures in the KO mice (WT: $27.2 \pm 2.1 \mu \mathrm{g} / \mathrm{g}, n=29$; KO: $35 \pm 0.3 \mu \mathrm{g} / \mathrm{g}$, $n=21$; unpaired two-tailed $t$ test, ${ }^{\star} p=0.043$; Fig. $7 G$ ), suggesting a reduced susceptibility to seizure induction. In summary, our $\mathrm{KO}$ mice lacked any sign of epileptiform activity and were, in contrast, more resistant to induction of seizures.

\section{Conditional deletion of Arc/Arg3.1 late in development does} not affect seizure susceptibility, social behavior, or amphetamine sensitivity

Although PFC activity was intact in late-cKO mice, absence of Arc/Arg3.1 in the adult brain could reduce brain plasticity, similar to knockdown of $A r c / A r g 3.1$ in adult rats (Guzowski et al., 2000; Messaoudi et al., 2007) and thereby induce schizophrenia-like behaviors. To test this possibility, we subjected late-cKO mice to several behavioral tests. First, we examined the dosage of kainic acid required to evoke generalized seizures in WT and late-cKO 
A
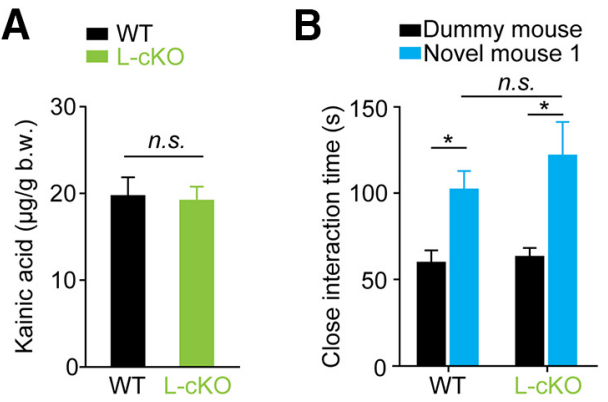

C

Novel mouse 1
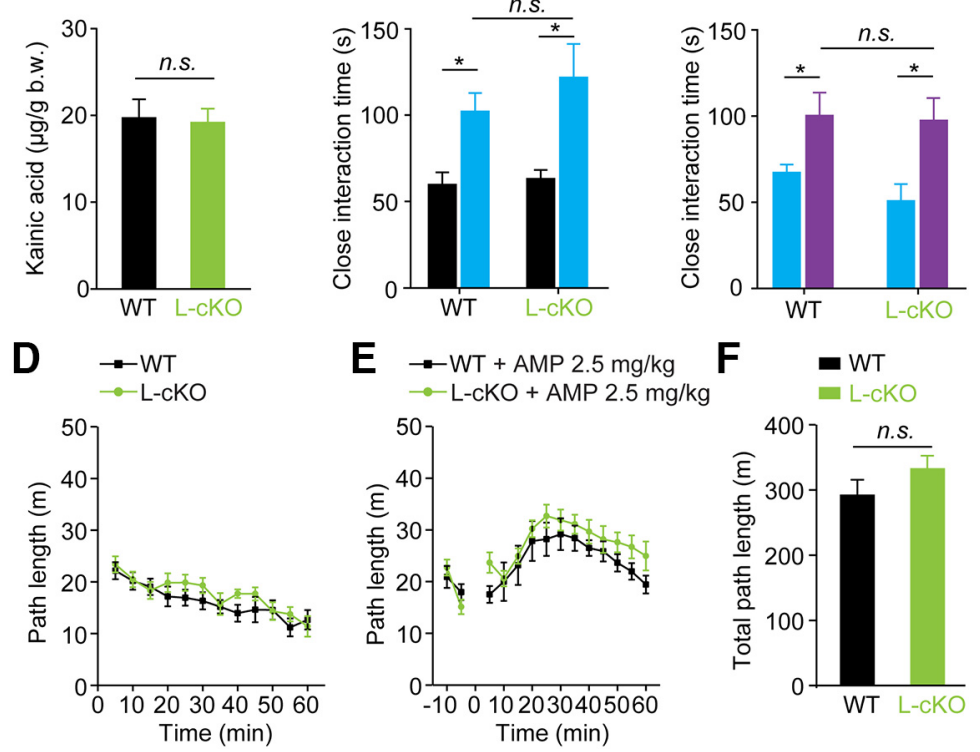

Figure 8. Conditional deletion of Arc/Arg3.1 late in development does not affect seizure susceptibility, social behavior, and amphetamine sensitivity. $A$, Comparable dosage of kainic acid is required to evoke generalized seizures in WT and L-cKO mice (WT: $n=12 ; \mathrm{L}-\mathrm{CKO}: n=14) . \boldsymbol{B}-\boldsymbol{C}$, Sociability and social novelty tests in L-cKO mice. $\boldsymbol{B}$, Both WT and L-cKO mice preferably interacted with Novel Mouse 1 rather than the Dummy Mouse during sociability test. C, Both WT and L-CKO mice preferably interacted with Novel Mouse 2 rather than Novel Mouse 1 during social novelty test. All WT: $n=7, \mathrm{~L}-\mathrm{cKO}: n=7$. D, Spontaneous locomotor activity was comparable in WT and L-cKO mice as indicated by similar path length during $1 \mathrm{~h}$ open-field test (WT: $n=8, \mathrm{~L}-\mathrm{KKO}: n=8$ ). $\boldsymbol{E}$, Indistinguishable locomotor response in WT and L-cKO mice when injected with $2.5 \mathrm{mg} / \mathrm{kg}$ body weight amphetamine intraperitoneally (WT: $n=8, \mathrm{~L}-\mathrm{CKO}: n=8$ ). $\boldsymbol{F}$, Similar total path length was generated in WT and L-cKO mice during $1 \mathrm{~h}$ exploration after injection with $2.5 \mathrm{mg} / \mathrm{kg}$ amphetamine. Bars show mean \pm SEM. Significance was tested with two-tailed two-sample $t$ test between groups in $\boldsymbol{A}-\boldsymbol{C}$ and $\boldsymbol{F}$. Paired $t$ test was performed within groups in $\boldsymbol{B}$ and $\boldsymbol{C}$. Two-way ANOVA with repeated measures was performed in $\boldsymbol{D}$ and $\boldsymbol{E}$. n.S., not significant, ${ }^{*} p<0.05$.

mice. Unlike KO mice, late-cKO mice developed generalized seizures in response to the same dosage of kainic acid as their WTcontrol littermates (unpaired two-tailed $t$ test, WT vs L-cKO: $t_{(24)}$ $=0.20 ; p=0.84$; WT: $n=12$; L-cKO: $n=14$; Fig. $8 A$ ), thereby exhibiting unaltered seizure susceptibility.

We next assessed the social behavior of the late-cKO mice to reveal a possible endophenotype of schizophrenia. Like KO mice, late-cKO mice preferred a living mouse over a Dummy Mouse (close interaction time Dummy Mouse vs Novel Mouse 1, paired two-tailed $t$ test, WT: $t_{(6)}=3.20,{ }^{*} p=0.019$; L-cKO: $t_{(6)}=2.82$, ${ }^{*} p=0.03$; close interaction time with Novel Mouse 1 WT vs L-cKO, unpaired two-tailed $t$ test, $t_{(12)}=-0.91, p=0.38 ; n=7$ and 7, respectively; Fig. $8 B$ ) and exhibited intact social preference to a second novel mouse (close interaction time Novel Mouse 1 vs Novel Mouse 2, paired two-tailed $t$ test, WT: $t_{(6)}=-2.94,{ }^{*} p=$ 0.026; L-cKO: $t_{(6)}=-2.78,{ }^{*} p=0.032$; close interaction time with Novel Mouse 2 WT vs L-cKO, unpaired two-tailed $t$ test, $t_{(12)}$ $=0.16, p=0.88$; Fig. $8 C$ ). Additionally, late-cKO mice displayed spontaneous locomotor activity similar to their WT littermates (two-way ANOVA with repeated measures, genotype: $F_{(1,14)}=$ $1.13, p=0.31$; time: $F_{(11,154)}=9.71, p<0.0001$; interaction: $F_{(11,154)}=0.72, p=0.72$, WT: $n=8$, L-cKO: $n=8$; Fig. $\left.8 D\right)$. Moreover, late-cKO mice did not display hypersensitivity when injected with amphetamine $(2.5 \mathrm{mg} / \mathrm{kg}$ body weight, i.p.), as shown by indistinguishable path lengths of WT and late-cKO mice (two-way ANOVA with repeated measures, genotype: $F_{(1,14)}=1.67, p=0.22$; time: $F_{(11,154)}=10.87, p<0.0001$; interaction: $F_{(11,154)}=0.52, p=0.89$; Fig. $8 E$; total path length WT vs L-cKO, unpaired two-tailed $t$ test: $t_{(14)}=-1.29 ; p=0.22$;
Fig. 8 F; all WT: $n=8$, L-cKO: $n=8$ ). These data further confirm that genetic ablation of $A r c / A r g 3.1$ by itself, before or during puberty, does not cause overt schizophrenia-like behavior in adult mice.

\section{Adolescent social isolation of WT and Arc/Arg3.1 KO mice does not affect social engagement and sensorimotor gating.}

Studies in animal models show that environmental stressors during adolescence can result in schizophrenia-like behaviors when combined with genetic risk factors (Niwa et al., 2013; Li et al., 2018). We addressed the effect of Arc/Arg3.1 genedeletion and environment assault by subjecting Arc/Arg3.1 KO mice and WT littermates to social isolation during puberty (Fig. 9A). Isolated adult WT and KO mice spent significantly longer times interacting with Novel Mouse 1 compared with Dummy Mouse (paired two-tailed $t$ test, WT: $t_{(11)}=-2.99,{ }^{\star} p=0.012$; KO: $t_{(6)}=-2.91,{ }^{*} p=0.027, \mathrm{WT}: n=12, \mathrm{KO}:$ $n=7$; Fig. $9 B$ ). WT mice, tested for social recognition, exhibited a significant preference to the Novel Mouse 2 (paired twotailed $t$ test, WT: $t_{(11)}=-3.48,{ }^{* *} p=$ 0.0051 ; Fig. 9C). KO mice exhibited a similar preference, however this did not reach significance $\left(\mathrm{KO}: t_{(6)}=-1.46, p=0.19\right.$; Fig. 9C). The interaction time with the Novel Mouse 2 was not significantly different between WT and $\mathrm{KO}$ mice (unpaired two-tailed $t$ test, $t_{(17)}=-0.26, p=0.79$ ). These data show that isolated WT and KO mice maintain intact social preference despite prolonged isolation. The same cohort of mice was subjected to the PPI test to probe a second schizophrenia-like behavior.

Isolated WT and KO mice generated comparable startle responses to the pulse stimulus (unpaired two-tailed $t$ test, WT vs $\mathrm{KO}: t_{(17)}=0.10, p=0.92$; WT: $n=12, \mathrm{KO}: n=7$; Fig. $\left.9 D\right)$ and consistently showed indistinguishable PPI rates at different prepulse intensities (two-way ANOVA with repeated measures, genotype: $F_{(1,17)}=0.55, p=0.47$; prepulse intensity: $F_{(4,68)}=$ 75.23, $p<0.0001$; interaction: $F_{(4,68)}=1.40, p=0.24$; Fig. $\left.9 E\right)$. The mean PPI rate was also similar between WT and KO mice (unpaired two-tailed $t$ test, WT vs KO: $t_{(17)}=-0.74, p=0.47$, $n=12,7$, respectively; Fig. $9 F$ ). Additionally, comparison of the startle responses of socially-isolated mice with the group-housed mice failed to detect any significant difference (all $p<0.05$; data not shown).

\section{Discussion}

Schizophrenia is a strongly heritable neuropsychiatric disease believed to arise from polygenetic and environmental risk factors that converge to disrupt normal brain development and provoke behavioral, neurological, and cognitive aberrations. Recent studies identified copy number variations (Kirov et al., 2012; Fernández et al., 2017), single nucleotide polymorphisms (Huentelman et al., 2015), and rare mutations (Fromer et al., 2014; Purcell et al., 2014) associated with high schizophrenia risk in genes whose 
products form complexes with Arc/ Arg3.1. Here we used constitutive and conditional Arc/Arg3.1 KO mice, which we previously generated (Plath et al., 2006; Gao et al., 2018) to investigate the impact of $A r c / A r g 3.1$ deletion on behavioral and neurological domains of schizophrenia. Examination of constitutive Arc/ Arg3.1 KO mice failed to identify any overt deficits in social interaction, working memory, sensorimotor gating, and locomotor activity. Reduced seizure susceptibility and decreased oscillatory activity in the PFC of the anesthetized KO and early-cKO mice are dissimilar to the excessive high-frequency cortical oscillations measured during resting state in schizophrenic patients (Spencer, 2011; Hirano et al., 2015). However, reduced brain oscillations during task performance have also been reported in human patients and animal models of schizophrenia (Lisman, 2012; Uhlhaas and Singer, 2015). Notably, late-cKO mice, in which Arc/Arg3.1 was deleted late in postnatal development, exhibited normal behaviors and intact PFC oscillatory activity. We hypothesize that early Arc/Arg3.1 expression in the PFC of late-cKO mice supports the normal formation of synaptic networks and maturation of oscillatory activity.

The interplay between excitation and inhibition is a key determinant of gain control in recurrent cortical networks (Douglas et al., 1995) performing cognitive algorithms such as working memory and perception. The biophysical properties of excitatory and inhibitory synapses influence oscillatory power and frequency (Buzsáki and Wang, 2012). The faster sIPSCs and reduced gain in the KO PFC may contribute to the impaired oscillations and learning and memory deficits in the $\mathrm{KO}$ mice (Plath et al., 2006; Gao et al., 2018). The finding that the E/I balance was preserved in the KO PFC can explain why despite changes in PFC circuitry and LFP, KO mice do not exhibit schizophrenia-like symptoms or epilepsy and are, in fact, more resilient to seizures. In both diseases disrupted E/I balance might be particularly critical for pathology (Lisman, 2012; Uhlhaas and Singer, 2015).

Reduced gephyrin clustering and fast decaying sIPSCs could result from a change in subunit composition of $\mathrm{GABA}_{\mathrm{A}}$ receptors, which is known to affect receptor kinetics and anchoring mechanism at the synapse (Fritschy et al., 2012). Reduced recurrent excitation to L5 PFC neurons without a concurrent reduction of sIPSC frequency could be a result of a loss of synaptic currents activated during recurrent but not spontaneous activity, for example NMDA receptor currents (Wang et al., 2008).

The normal spontaneous locomotion of the Arc/Arg3.1 KO mice does not recapitulate hyperlocomotion observed in schizophrenic patients (Perry et al., 2010). Moreover, amphetamineinduced locomotion was far weaker and shorter in the Arc/Arg3.1 KO compared with other rodent models with relevance to schizophrenia (van den Buuse, 2010; Young et al., 2016). In the absence of other dopaminergic or behavioral abnormalities, we speculate that the transient amphetamine response reflects direct or circuit-level modifications in serotonergic, adrenergic (van den
B
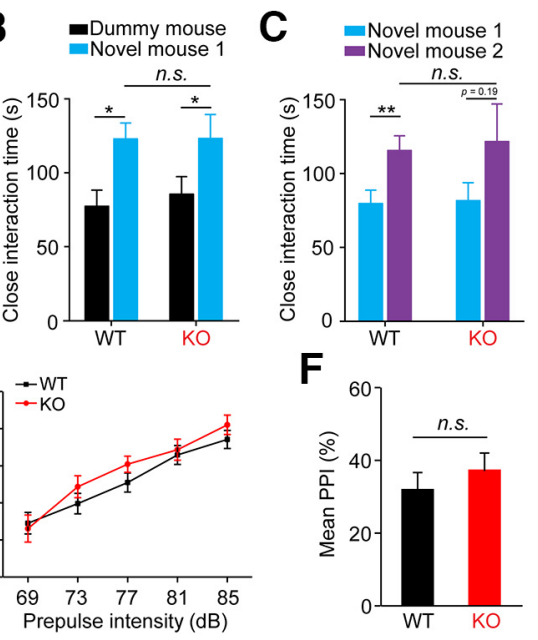
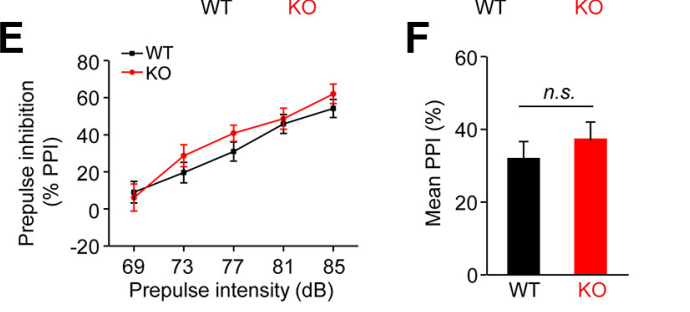

Figure 9. Adolescent social isolation does not affect social engagement or sensorimotor gating in adult $\operatorname{Arc} / \operatorname{Arg} 3.1 \mathrm{KO}$ mice. $\boldsymbol{A}$, $\boldsymbol{D}$ and $\boldsymbol{F}$. Two-way ANOVA with repeated measures was applied in $\boldsymbol{E}$. All WT: $n=12, \mathrm{KO}: n=7$. Bars show mean \pm SEM. n.S., not significant, ${ }^{*} p<0.05,{ }^{* *} p<0.01$. Sl, social interaction.

Buuse et al., 2011; Schmidt and Weinshenker, 2014), or glutamatergic transmission (Coyle, 2006).

Environmental stressors during adolescence are considered high-risk factors for schizophrenia, especially when combined with genetic aberrations. Social isolation during adolescence has been shown to induce depression and schizophrenia-like behaviors in mice harboring genetic mutations linked-to schizophrenia, but not in WT mice (Niwa et al., 2013; Li et al., 2018). Subjecting Arc/Arg3.1 KO mice to this stressor did not result in deficits in social behavior or PPI. These data indicate that Arc/ Arg3.1 deletions combined with subthreshold insults do not suffice to manifest schizophrenia-like behaviors.

Our findings are in disagreement with a recent study reporting overt schizophrenia-related phenotypes in a different Arc/Arg3.1 KO mouse model (Managò et al., 2016). In this study, Arc/Arg3.1deficient mice (EGFP knock-in-Arc/Arg3.1 knock-out), displayed strongly impaired social interaction and PPI, as well as amphetamine hypersensitivity, and dopaminergic dysregulation. In stark contrast, using similar experimental procedures, we found no apparent schizophrenia-related phenotype in our $\mathrm{KO}$ mice. These contradicting observations might be reconciled and explained by the different strategies used for generating the two KO mouse models. The mouse model used by Managò et al. (2016) was generated by knocking into the Arc/Arg3.1 open reading frame (ORF) a d2EGFP sequence terminated by a stop codon and followed by a floxed neomycin cassette, which has not been removed in the mutant mice (Wang et al., 2006). The neomycin cassette in these KO mice (EGFP knock-in-Arc/Arg3.1 knockout) could potentially produce adverse effects (Scacheri et al., 2001), such as disruption of neighboring gene expression (Pham et al., 1996), which is not seen in the WT littermates that do not carry the neomycin cassette. For example, it would be interesting to see whether the neomycin cassette could interfere with the expression of JRK and LYNX1, two epilepsy-related genes whose loci are close to the Arc/Arg3.1 gene on mouse chromosome 15 (MGI: 88067, NCBI Gene: 11838). This interference might pro- 
mote epilepsy (Toth et al., 1995; Smith et al., 2018) and facilitate schizophrenia pathogenesis. Indeed, a different study using the same EGFP knock-in-Arc/Arg3.1 KO mice reported inter-ictal brain activity and higher seizure susceptibility (Peebles et al., 2010), in stark contrast to what we observed in our KO mice. Therefore, the EGFP knock-in-Arc/Arg3.1 knock-out mice might serve as an interesting model for investigating the convergence of Arc/Arg3.1 deletion and polygenetic dysregulation, if effects of the neomycin cassette can be isolated. In a less fortunate scenario, merely the expression of the selectable marker or the knocked in EGFP might have adverse effects on cell physiology or promote apoptosis (Müller, 1999; Jensen, 2012; Ansari et al., 2016).

Arc/Arg3.1 expression during early brain development (before puberty) shapes oscillatory activity in the PFC of adult mice similar to the effects we observed in the hippocampus (Gao et al., 2018). Our current findings reveal alterations in excitatory and inhibitory neurotransmission in the PFC as likely underlying mechanisms. These alterations may result from impaired Arc/ Arg3.1-mediated plasticity during development, such as homeostatic synaptic scaling (Chowdhury et al., 2006; Shepherd et al., 2006), synapse pruning (Mikuni et al., 2013), or synaptic plasticity (Plath et al., 2006; Rial Verde et al., 2006). These mechanisms are disrupted in some neurodevelopmental disorders, including schizophrenia (Feinberg, 1982; Crabtree and Gogos, 2014).

Together, our findings demonstrate that the loss of Arc/Arg3.1 per se does not induce schizophrenia-like behavior in adult mice. However, prenatal or perinatal deletion of Arc/Arg3.1 alters cortical network activity without overtly disrupting the balance of excitation and inhibition in the brain and not promoting schizophrenia. Misregulation of Arc/Arg3.1 rather than deletion could potentially tip this balance and thereby promote emergence of schizophrenia and other neuropsychiatric disorders.

\section{References}

Amzica F, Steriade M (1997) The K-complex: its slow (<1-Hz) rhythmicity and relation to delta waves. Neurology 49:952-959.

Ansari AM, Ahmed AK, Matsangos AE, Lay F, Born LJ, Marti G, Harmon JW, Sun Z (2016) Cellular GFP toxicity and immunogenicity: potential confounders in in vivo cell tracking experiments. Stem Cell Rev Rep 12:553559.

Birnbaum R, Weinberger DR (2017) Genetic insights into the neurodevelopmental origins of schizophrenia. Nat Rev Neurosci 18:727-740.

Braff DL, Geyer MA, Swerdlow NR (2001) Human studies of prepulse inhibition of startle: normal subjects, patient groups, and pharmacological studies. Psychopharmacology 156:234-258.

Buzsáki G, Wang XJ (2012) Mechanisms of gamma oscillations. Annu Rev Neurosci 35:203-225.

Cao C, Rioult-Pedotti MS, Migani P, Yu CJ, Tiwari R, Parang K, Spaller MR, Goebel DJ, Marshall J (2013) Impairment of TrkB-PSD-95 signaling in Angelman syndrome. PLoS Biol 11:e1001478.

Casanova E, Fehsenfeld S, Mantamadiotis T, Lemberger T, Greiner E, Stewart AF, Schütz G (2001) A CamKII $\alpha$ iCre BAC allows brain-specific gene inactivation. Genesis 31:37-42.

Chowdhury S, Shepherd JD, Okuno H, Lyford G, Petralia RS, Plath N, Kuhl D, Huganir RL, Worley PF (2006) Arc/Arg3.1 interacts with the endocytic machinery to regulate AMPA receptor trafficking. Neuron 52:445459.

Clapcote SJ, Lipina TV, Millar JK, Mackie S, Christie S, Ogawa F, Lerch JP, Trimble K, Uchiyama M, Sakuraba Y, Kaneda H, Shiroishi T, Houslay MD, Henkelman RM, Sled JG, Gondo Y, Porteous DJ, Roder JC (2007) Behavioral phenotypes of Discl missense mutations in mice. Neuron 54:387-402.

Clarke MC, Tanskanen A, Huttunen MO, Clancy M, Cotter DR, Cannon M (2012) Evidence for shared susceptibility to epilepsy and psychosis: a population-based family study. Biol Psychiatry 71:836-839.

Coyle JT (2006) Glutamate and schizophrenia: beyond the dopamine hypothesis. Cell Mol Neurobiol 26:365-384.
Crabtree GW, Gogos JA (2014) Synaptic plasticity, neural circuits, and the emerging role of altered short-term information processing in schizophrenia. Front Synaptic Neurosci 6:28.

Dember WN, Fowler H (1958) Spontaneous alternation behavior. Psychol Bull 55:412-428.

Douglas RJ, Koch C, Mahowald M, Martin KA, Suarez HH (1995) Recurrent excitation in neocortical circuits. Science 269:981-985.

El-Boustani S, Ip JPK, Breton-Provencher V, Knott GW, Okuno H, Bito H, Sur M (2018) Locally coordinated synaptic plasticity of visual cortex neurons in vivo. Science 360:1349-1354.

Fazeli W, Zappettini S, Marguet SL, Grendel J, Esclapez M, Bernard C, Isbrandt D (2017) Early-life exposure to caffeine affects the construction and activity of cortical networks in mice. Exp Neurol 295:88-103.

Feinberg I (1982) Schizophrenia: caused by a fault in programmed synaptic elimination during adolescence? J Psychiatr Res 17:319-334.

Fejgin K, Nielsen J, Birknow MR, Bastlund JF, Nielsen V, Lauridsen JB, Stefansson H, Steinberg S, Sorensen HB, Mortensen TE, Larsen PH, Klewe IV, Rasmussen SV, Stefansson K, Werge TM, Kallunki P, Christensen KV, Didriksen M (2014) A mouse model that recapitulates cardinal features of the 15q13.3 microdeletion syndrome including schizophrenia- and epilepsy-related alterations. Biol Psychiatry 76:128-137.

Fernández E, Collins MO, Frank RAW, Zhu F, Kopanitsa MV, Nithianantharajah J, Lemprière SA, Fricker D, Elsegood KA, McLaughlin CL, Croning MDR, Mclean C, Armstrong JD, Hill WD, Deary IJ, Cencelli G, Bagni C, Fromer M, Purcell SM, Pocklington AJ, et al. (2017) Arc requires PSD95 for assembly into postsynaptic complexes involved with neural dysfunction and intelligence. Cell Rep 21:679-691.

Fritschy JM, Panzanelli P, Tyagarajan SK (2012) Molecular and functional heterogeneity of GABAergic synapses. Cell Mol Life Sci 69:2485-2499.

Fromer M, Pocklington AJ, Kavanagh DH, Williams HJ, Dwyer S, Gormley P, Georgieva L, Rees E, Palta P, Ruderfer DM, Carrera N, Humphreys I, Johnson JS, Roussos P, Barker DD, Banks E, Milanova V, Grant SG, Hannon E, Rose SA, et al. (2014) De novo mutations in schizophrenia implicate synaptic networks. Nature 506:179-184.

Gao X, Castro-Gomez S, Grendel J, Graf S, Süsens U, Binkle L, Mensching D, Isbrandt D, Kuhl D, Ohana O (2018) Arc/Arg3.1 mediates a critical period for spatial learning and hippocampal networks. Proc Natl Acad Sci U S A 115:12531-12536.

Greer PL, Hanayama R, Bloodgood BL, Mardinly AR, Lipton DM, Flavell SW, Kim TK, Griffith EC, Waldon Z, Maehr R, Ploegh HL, Chowdhury S, Worley PF, Steen J, Greenberg ME (2010) The angelman syndrome protein Ube3A regulates synapse development by ubiquitinating arc. Cell 140:704-716.

Guzowski JF, Lyford GL, Stevenson GD, Houston FP, McGaugh JL, Worley PF, Barnes CA (2000) Inhibition of activity-dependent arc protein expression in the rat hippocampus impairs the maintenance of long-term potentiation and the consolidation of long-term memory. J Neurosci 20:3993-4001.

Haß K, Bak N, Szycik GR, Glenthøj BY, Oranje B (2017) Deficient prepulse inhibition of the startle reflex in schizophrenia using a cross-modal paradigm. Biol Psychol 128:112-116.

Hazan L, Zugaro M, Buzsáki G (2006) Klusters, NeuroScope, NDManager: a free software suite for neurophysiological data processing and visualization. J Neurosci Methods 155:207-216.

Hermey G, Mahlke C, Gutzmann JJ, Schreiber J, Blüthgen N, Kuhl D (2013) Genome-wide profiling of the activity-dependent hippocampal transcriptome. PLoS One 8:e76903.

Hirano Y, Oribe N, Kanba S, Onitsuka T, Nestor PG, Spencer KM (2015) Spontaneous gamma activity in schizophrenia. JAMA Psychiatry 72:813821.

Howes OD, Kapur S (2009) The dopamine hypothesis of schizophrenia: version III-the final common pathway. Schizophr Bull 35:549-562.

Howes O, McCutcheon R, Stone J (2015) Glutamate and dopamine in schizophrenia: an update for the 21st century. J Psychopharmacol 29:97115.

Huentelman MJ, Muppana L, Corneveaux JJ, Dinu V, Pruzin JJ, Reiman R, Borish CN, De Both M, Ahmed A, Todorov A, Cloninger CR, Zhang R, Ma J, Gallitano AL (2015) Association of SNPs in EGR3 and ARC with schizophrenia supports a biological pathway for schizophrenia risk. PLoS One 10:e135076.

Hunt MJ, Kopell NJ, Traub RD, Whittington MA (2017) Aberrant network activity in schizophrenia. Trends Neurosci 40:371-382. 
Jakkamsetti V, Tsai NP, Gross C, Molinaro G, Collins KA, Nicoletti F, Wang KH, Osten P, Bassell GJ, Gibson JR, Huber KM (2013) Experienceinduced Arc/Arg3.1 primes CA1 pyramidal neurons for metabotropic glutamate receptor-dependent long-term synaptic depression. Neuron 80:72-79.

Jefferys JG (2010) Advances in understanding basic mechanisms of epilepsy and seizures. Seizure 19:638-646.

Jensen EC (2012) Use of fluorescent probes: their effect on cell biology and limitations. Anat Rec (Hoboken) 295:2031-2036.

Kirov G, Pocklington AJ, Holmans P, Ivanov D, Ikeda M, Ruderfer D, Moran J, Chambert K, Toncheva D, Georgieva L, Grozeva D, Fjodorova M, Wollerton R, Rees E, Nikolov I, van de Lagemaat LN, Bayés A, Fernandez E, Olason PI, Böttcher Y, et al. (2012) De novo CNV analysis implicates specific abnormalities of postsynaptic signalling complexes in the pathogenesis of schizophrenia. Mol Psychiatry 17:142-153.

Lalonde R (2002) The neurobiological basis of spontaneous alternation. Neurosci Biobehav Rev 26:91-104.

Lett TA, Voineskos AN, Kennedy JL, Levine B, Daskalakis ZJ (2014) Treating working memory deficits in schizophrenia: a review of the neurobiology. Biol Psychiatry 75:361-370.

Li N, Cui L, Song G, Guo L, Gu H, Cao H, Li GD, Zhou Y (2018) Adolescent isolation interacts with DISC1 point mutation to impair adult social memory and synaptic functions in the hippocampus. Front Cell Neurosci 12:238.

Link W, Konietzko U, Kauselmann G, Krug M, Schwanke B, Frey U, Kuhl D (1995) Somatodendritic expression of an immediate early gene is regulated by synaptic activity. Proc Natl Acad Sci U S A 92:5734-5738.

Lisman J (2012) Excitation, inhibition, local oscillations, or large-scale loops: what causes the symptoms of schizophrenia? Curr Opin Neurobiol 22:537-544.

Lyford GL, Yamagata K, Kaufmann WE, Barnes CA, Sanders LK, Copeland NG, Gilbert DJ, Jenkins NA, Lanahan AA, Worley PF (1995) Arc, a growth factor and activity-regulated gene, encodes a novel cytoskeletonassociated protein that is enriched in neuronal dendrites. Neuron 14:433445.

Mäkikyrö T, Karvonen JT, Hakko H, Nieminen P, Joukamaa M, Isohanni M, Jones P, Järvelin MR (1998) Comorbidity of hospital-treated psychiatric and physical disorders with special reference to schizophrenia: a 28 year follow-up of the 1966 northern Finland general population birth cohort. Public Health 112:221-228.

Managò F, Mereu M, Mastwal S, Mastrogiacomo R, Scheggia D, Emanuele M, De Luca MA, Weinberger DR, Wang KH, Papaleo F (2016) Genetic disruption of Arc/Arg3.1 in mice causes alterations in dopamine and neurobehavioral phenotypes related to schizophrenia. Cell Rep 16:2116-2128.

Mandel-Brehm C, Salogiannis J, Dhamne SC, Rotenberg A, Greenberg ME (2015) Seizure-like activity in a juvenile Angelman syndrome mouse model is attenuated by reducing Arc expression. Proc Natl Acad Sci U S A 112:5129-5134.

Marguet SL, Le-Schulte VT, Merseburg A, Neu A, Eichler R, Jakovcevski I, Ivanov A, Hanganu-Opatz IL, Bernard C, Morellini F, Isbrandt D (2015) Treatment during a vulnerable developmental period rescues a genetic epilepsy. Nat Med 21:1436-1444.

Marini G, Ceccarelli P, Mancia M (2004) Spontaneous K-complexes in behaving rats. Arch Ital Biol 142:59-67.

Mena A, Ruiz-Salas JC, Puentes A, Dorado I, Ruiz-Veguilla M, De la Casa LG (2016) Reduced prepulse inhibition as a biomarker of schizophrenia. Front Behav Neurosci 10:202.

Messaoudi E, Kanhema T, Soulé J, Tiron A, Dagyte G, da Silva B, Bramham CR (2007) Sustained Arc/Arg3.1 synthesis controls long-term potentiation consolidation through regulation of local actin polymerization in the dentate gyrus in vivo. J Neurosci 27:10445-10455.

Mikuni T, Uesaka N, Okuno H, Hirai H, Deisseroth K, Bito H, Kano M (2013) Arc/Arg3.1 is a postsynaptic mediator of activity-dependent synapse elimination in the developing cerebellum. Neuron 78:1024-1035.

Modai S, Shomron N (2016) Molecular risk factors for schizophrenia. Trends Mol Med 22:242-253.

Müller U (1999) Ten years of gene targeting: targeted mouse mutants, from vector design to phenotype analysis. Mech Dev 82:3-21.

Niere F, Wilkerson JR, Huber KM (2012) Evidence for a fragile X mental retardation protein-mediated translational switch in metabotropic gluta- mate receptor-triggered arc translation and long-term depression. J Neurosci 32:5924-5936.

Niwa M, Jaaro-Peled H, Tankou S, Seshadri S, Hikida T, Matsumoto Y, Cascella NG, Kano S, Ozaki N, Nabeshima T, Sawa A (2013) Adolescent stress-induced epigenetic control of dopaminergic neurons via glucocorticoids. Science 339:335-339.

Ohana O, Portner H, Martin KA (2012) Fast recruitment of recurrent inhibition in the cat visual cortex. PLoS One 7:e40601.

Owen MJ, Sawa A, Mortensen PB (2016) Schizophrenia. Lancet 388:86-97.

Peebles CL, Yoo J, Thwin MT, Palop JJ, Noebels JL, Finkbeiner S (2010) Arc regulates spine morphology and maintains network stability in vivo. Proc Natl Acad Sci U S A 107:18173-18178.

Perry W, Minassian A, Henry B, Kincaid M, Young JW, Geyer MA (2010) Quantifying over-activity in bipolar and schizophrenia patients in a human open field paradigm. Psychiatry Res 178:84-91.

Peters HC, Hu H, Pongs O, Storm JF, Isbrandt D (2005) Conditional transgenic suppression of $\mathrm{M}$ channels in mouse brain reveals functions in neuronal excitability, resonance and behavior. Nat Neurosci 8:51-60.

Pham CT, MacIvor DM, Hug BA, Heusel JW, Ley TJ (1996) Long-range disruption of gene expression by a selectable marker cassette. Proc Natl Acad Sci U S A 93:13090-13095.

Plath N, Ohana O, Dammermann B, Errington ML, Schmitz D, Gross C, Mao X, Engelsberg A, Mahlke C, Welzl H, Kobalz U, Stawrakakis A, Fernandez E, Waltereit R, Bick-Sander A, Therstappen E, Cooke SF, Blanquet V, Wurst W, Salmen B, et al. (2006) Arc/Arg3.1 is essential for the consolidation of synaptic plasticity and memories. Neuron 52:437-444.

Prox J, Bernreuther C, Altmeppen H, Grendel J, Glatzel M, D’Hooge R, Stroobants S, Ahmed T, Balschun D, Willem M, Lammich S, Isbrandt D, Schweizer M, Horré K, De Strooper B, Saftig P (2013) Postnatal disruption of the disintegrin/metalloproteinase ADAM10 in brain causes epileptic seizures, learning deficits, altered spine morphology, and defective synaptic functions. J Neurosci 33:12915-12928.

Purcell SM, Moran JL, Fromer M, Ruderfer D, Solovieff N, Roussos P, O’Dushlaine C, Chambert K, Bergen SE, Kähler A, Duncan L, Stahl E, Genovese G, Fernández E, Collins MO, Komiyama NH, Choudhary JS, Magnusson PK, Banks E, Shakir K, et al. (2014) A polygenic burden of rare disruptive mutations in schizophrenia. Nature 506:185-190.

Qin P, Xu H, Laursen TM, Vestergaard M, Mortensen PB (2005) Risk for schizophrenia and schizophrenia-like psychosis among patients with epilepsy: population based cohort study. BMJ 331:23.

Rapoport JL, Giedd JN, Gogtay N (2012) Neurodevelopmental model of schizophrenia: update 2012. Mol Psychiatry 17:1228-1238.

Rial Verde EM, Lee-Osbourne J, Worley PF, Malinow R, Cline HT (2006) Increased expression of the immediate-early gene $\operatorname{Arc} / \operatorname{Arg} 3.1$ reduces AMPA receptor-mediated synaptic transmission. Neuron 52:461-474.

Ronesi JA, Collins KA, Hays SA, Tsai NP, Guo W, Birnbaum SG, Hu JH, Worley PF, Gibson JR, Huber KM (2012) Disrupted homer scaffolds mediate abnormal mGluR5 function in a mouse model of fragile X syndrome. Nat Neurosci 15:431-440.

Sanderson DJ, Bannerman DM (2012) The role of habituation in hippocampus-dependent spatial working memory tasks: evidence from GluA1 AMPA receptor subunit knock-out mice. Hippocampus 22:981994.

Sano W, Nakamura T, Yoshiuchi K, Kitajima T, Tsuchiya A, Esaki Y, Yamamoto Y, Iwata N (2012) Enhanced persistency of resting and active periods of locomotor activity in schizophrenia. PLoS One 7:e43539.

Scacheri PC, Crabtree JS, Novotny EA, Garrett-Beal L, Chen A, Edgemon KA, Marx SJ, Spiegel AM, Chandrasekharappa SC, Collins FS (2001) Bidirectional transcriptional activity of PGK-neomycin and unexpected embryonic lethality in heterozygote chimeric knockout mice. Genesis 30: $259-263$

Schmidt KT, Weinshenker D (2014) Adrenaline rush: the role of adrenergic receptors in stimulant-induced behaviors. Mol Pharmacol 85:640-650.

Seeman P, Weinshenker D, Quirion R, Srivastava LK, Bhardwaj SK, Grandy DK, Premont RT, Sotnikova TD, Boksa P, El-Ghundi M, O'Dowd BF, George SR, Perreault ML, Männistö PT, Robinson S, Palmiter RD, Tallerico T (2005) Dopamine supersensitivity correlates with D2High states, implying many paths to psychosis. Proc Natl Acad Sci U S A 102: 3513-3518.

Shepherd JD, Rumbaugh G, Wu J, Chowdhury S, Plath N, Kuhl D, Huganir RL, Worley PF (2006) Arc/Arg3.1 mediates homeostatic synaptic scaling of AMPA receptors. Neuron 52:475-484. 
Shin M, Brager D, Jaramillo TC, Johnston D, Chetkovich DM (2008) Mislocalization of $\mathrm{h}$ channel subunits underlies $\mathrm{h}$ channelopathy in temporal lobe epilepsy. Neurobiol Dis 32:26-36.

Smith MR, Glicksberg BS, Li L, Chen R, Morishita H, Dudley JT (2018) Loss-of-function of neuroplasticity-related genes confers risk for human neurodevelopmental disorders. Pac Symp Biocomput 23:68-79.

Song AJ, Palmiter RD (2018) Detecting and avoiding problems when using the cre-lox system. Trends Genet 34:333-340.

Spencer KM (2011) Baseline gamma power during auditory steady-state stimulation in schizophrenia. Front Hum Neurosci 5:190.

Swerdlow NR, Light GA, Thomas ML, Sprock J, Calkins ME, Green MF, Greenwood TA, Gur RE, Gur RC, Lazzeroni LC, Nuechterlein KH, Radant AD, Seidman LJ, Siever LJ, Silverman JM, Stone WS, Sugar CA, Tsuang DW, Tsuang MT, Turetsky BI, et al. (2018) Deficient prepulse inhibition in schizophrenia in a multi-site cohort: internal replication and extension. Schizophr Res 198:6-15.

Swerdlow NR, Weber M, Qu Y, Light GA, Braff DL (2008) Realistic expectations of prepulse inhibition in translational models for schizophrenia research. Psychopharmacology 199:331-388.

Toda M, Abi-Dargham A (2007) Dopamine hypothesis of schizophrenia: making sense of it all. Curr Psychiatry Rep 9:329-336.

Toth M, Grimsby J, Buzsaki G, Donovan GP (1995) Epileptic seizures caused by inactivation of a novel gene, jerky, related to centromere binding protein-B in transgenic mice. Nat Genet 11:71-75.

Tsien JZ, Chen DF, Gerber D, Tom C, Mercer EH, Anderson DJ, Mayford M, Kandel ER, Tonegawa S (1996) Subregion- and cell type-restricted gene knockout in mouse brain. Cell 87:1317-1326.
Uhlhaas PJ, Singer W (2015) Oscillations and neuronal dynamics in schizophrenia: the search for basic symptoms and translational opportunities. Biol Psychiatry 77:1001-1009.

van Aerde KI, Feldmeyer D (2015) Morphological and physiological characterization of pyramidal neuron subtypes in rat medial prefrontal cortex. Cereb Cortex 25:788-805.

van den Buuse M (2010) Modeling the positive symptoms of schizophrenia in genetically modified mice: pharmacology and methodology aspects. Schizophr Bull 36:246-270.

van den Buuse M, Ruimschotel E, Martin S, Risbrough VB, Halberstadt AL (2011) Enhanced effects of amphetamine but reduced effects of the hallucinogen, 5-MeO-DMT, on locomotor activity in 5- $\mathrm{HT}_{1 \mathrm{~A}}$ receptor knockout mice: implications for schizophrenia. Neuropharmacology 61:209-216.

van Os J, Kapur S (2009) Schizophrenia. Lancet 374:635-645.

Wang H, Stradtman GG 3rd, Wang XJ, Gao WJ (2008) A specialized NMDA receptor function in layer 5 recurrent microcircuitry of the adult rat prefrontal cortex. Proc Natl Acad Sci U S A 105:16791-16796.

Wang KH, Majewska A, Schummers J, Farley B, Hu C, Sur M, Tonegawa S (2006) In vivo two-photon imaging reveals a role of arc in enhancing orientation specificity in visual cortex. Cell 126:389-402.

Waung MW, Pfeiffer BE, Nosyreva ED, Ronesi JA, Huber KM (2008) Rapid translation of Arc/Arg3.1 selectively mediates mGluR-dependent LTD through persistent increases in AMPAR endocytosis rate. Neuron 59:84-97.

Young JW, Minassian A, Geyer MA (2016) Locomotor profiling from rodents to the clinic and back again. Curr Top Behav Neurosci 28:287-303. 